\title{
A Prospective, Randomized Comparison of Functional Bracing Versus Rigid Immobilization after Modified Percutaneous Achilles Tendon Repair Under Local Anesthesia
}

\author{
ANDREJ CRETNIK ( $\nabla$ andrej.cretnik@guest.arnes.si ) \\ University Medical Center Maribor https://orcid.org/0000-0001-5836-8869 \\ Roman Košir \\ University Clinical Center Maribor
}

\section{Research article}

Keywords: Achilles tendon, percutaneous repair, local anesthesia, functional treatment, early mobilization, rigid immobilization

Posted Date: November 5th, 2020

DOI: https://doi.org/10.21203/rs.3.rs-101440/v1

License: (c) (i) This work is licensed under a Creative Commons Attribution 4.0 International License. Read Full License

Version of Record: A version of this preprint was published at Arthroscopy: The Journal of Arthroscopic \& Related Surgery on September 1st, 2012. See the published version at https://doi.org/10.1016/j.arthro.2012.05.733. 


\section{Abstract}

Background: There is ongoing controversy over the optimal treatment and rehabilitation strategy of an acute Achilles tendon rupture (ATR). Percutaneous suturing seems to bridge the gap between open surgical and conservative treatment, but still raises scepticism due to concerns like strength of the repair, approximation of torn ends, re-rupture rate, sural nerve injuries, early functional rehabilitation and thus final outcome. The purpose of the study was to analyze the results of two ways of postoperative regimen after treatment with the modified and biomechanically significantly stronger percutaneous repair under local anesthesia.

Methods: In a prospective, randomized study from the year 2001 to 2004, with a 3-year follow-up, there were 31 patients (32 ruptures) in the functional bracing group (FG) and 30 patients, who wore rigid immobilization for the period of 6 weeks (IG).

Results: Both groups were comparable for gender ( 3 vs 2 women) and average age (41.93 years, SD \pm 12.29 vs 42.20 years, $S D \pm 10.53)$. Most ATRs were sports related ( $62.5 \%$ in FG vs $60.0 \%$ in IG). There was $1(3.3 \%)$ rerupture in IG and no re-rupture in FG (1.6\% altogether), 2 (6.2\%) transient sural nerve disturbances in $\mathrm{FG}$ and 1 $(3.3 \%)$ in IG (4.8\% altogether), one suture extrusion problem in IG $(3.3 \%)$ with no other major or minor complications (6.2\% of altogether complications in FG vs $10.0 \%$ in IG) $(p>0.05)$ (overall $8.1 \%$ ). Patients in FG were (subjectively) more satisfied with the treatment, reached sooner final range of motion (ROM) and muscular strength without limping and had higher average AOFAS score $(96.87$ vs 95.96$)(p>0.05)$. There were no statistically significant differences observed between groups according to final ROM, strength and return to pre-injury activities or sports.

Conclusions: The results of the study support the choice of presented modified percutaneous suturing under local anesthesia with functional treatment and early mobilization as a reasonable treatment option for an acute ATR.

Trial registration: $\mathrm{KME}, 54 / 03 / 00,21.03 .2000$

\section{Background}

Despite increased interest and several articles in the last decades the optimal treatment of an acute complete Achilles tendon rupture (ATR) remains controversial. Treatment can be broadly classified into conservative management with cast immobilization or functional bracing [1-14] and operative management with open repair (with or without augmentation) $[2-4,6-8,10,11,13-19]$ or minimally invasive procedures with closed percutaneous repair [20-22] or semi-open techniques [23-28] with possible ultrasonography guidance [29, 30] or endoscopic control [31-33]. Postoperative rehabilitation protocols include traditionally nonweightbearing, bellow knee cast immobilization (generally for 6 to 8 weeks) and in last decades mainly functional accelerated rehabilitation with functional bracing for 6 weeks, early ankle motion exercises and early weightbearing $[5,9-$ $14,19,24,30,34]$.

Meta-analyses and quantitative reviews of the literature regarding the management of ATRs have shown that open operative treatment was associated with a lower risk of rerupture (pooled rate of $1.4 \%$ [35], 2.1\% [36], 2.2\% [37], 3.0\% [38], 3.5\% [39], 3.6\% [40], 3.7\% [41], 3.8\% [42], 4.4\% [43] and 5.0\% [44]), than nonoperative 
management (pooled rate of 2.4\% [36], 8.8\% [40], 9.8\% [35], 9.8\% [41], 10.6\% [43], 11.9\% [42], 12.0\% [44], 12.1\% [37], $12.6 \%$ [39] and 13.0\% [38]. Ochen et al. found in their recently published systematic review and metaanalysis of 10 randomized controlled trials involving 944 patients and 19 observational studies including 14918 patients, a significant reduction in re-ruptures after operative treatment $(2.3 \%)$ compared with nonoperative treatment (3.9\%) (risk difference $1.6 \%$; risk ratio $0.43,95 \%$ confidence interval 0.31 to $0.60 ; p<$ $0.001 ; I^{2}=22 \%$ ) [45]. Operative treatment resulted but in a significantly higher complication rate than nonoperative treatment (4.9\% vs $1.6 \%$; risk difference $3.3 \%$; risk ratio $2.76,1.84$ to $4.13 ; p<0.001 ;\left.\right|^{2}=45 \%$ ) [45]. Khan et al. found in their study that risk of other complications could be diminished by percutaneous repair (pooled rate of $26.1 \%$ in the open group vs. pooled rate of $8.3 \%$ in the percutaneous group) [39]. Wong et al. found, analyzing 5370 patients in 193 articles, the lowest general complication rates with open repair and early mobilization (6.7\%) but the highest in patients treated with percutaneous repair and early mobilization (15.6\%) [35]. In a recent systematic review and network meta-analysis of 2060 patients in 29 randomized controlled trials Wu et al. found $7.41 \%$ of overall complication rates in the group of open surgery and accelerated rehabilitation in comparison to $8.47 \%$ in the group of minimally invasive surgery and accelerated rehabilitation, $12.09 \%$ in nonsurgery group and accelerated rehabilitation and $13.97 \%$ in nonsurgery group and early immobilization [46]. The mean incidence of overall major complications from all managements was $9.13 \%$ (median, 6.67\%) [46].

Concept of early dynamic functional rehabilitation has dramatically changed the results in a term of re-rupture rate of conservative treatment of ATR. Soroceanu et al. found in a meta-analysis of 10 randomized trials in 418 surgically treated patients and in 408 patients who underwent nonsurgical treatment, if functional rehabilitation with early range of motion (ROM) was employed, re-rupture rates were equal for surgical and nonsurgical patients (risk difference $=1.7 \%, p=0.45$ ) [47]. If such early ROM was not employed, the absolute risk reduction achieved by surgery was $8.8 \%(p=0.001$ in favor of surgery) [47]. Similar findings were also found in a study with stratifying (sub)groups by Khan et al. in nonoperatively treated patients (pooled data revealed a re-rupture rate of $2.4 \%$ ( 1 of 41 patients) in the functional bracing group and $12.2 \%$ (6 of 46 patients) in the casting group) (relative risk, 3.59; $95 \%$ confidence interval, 0.59 to 21.76), as well as with operative treatment (pooled rate of re-rupture was $5.0 \%$ (7 of 140 patients) in the cast immobilization group and $2.3 \%$ (3 of 133 patients) in the functional bracing group (relative risk, $2.04 ; 95 \%$ confidence interval, 0.59 to 7.06) [39]. Jones et al. also noticed in the studies that compared cast immobilization with accelerated rehabilitation, that pooled re-rupture rate in nonoperatively treated patients was $3.3 \%$ ( 2 of 60 patients) in the accelerated rehabilitation group compared with $11.4 \%$ (8 of 70 patients) in the cast immobilization group [43]. Ochen et al. found in their systematic review and meta-analysis no statistically significant difference in rerupture rate between operative and nonoperative treatment in studies that used accelerated functional rehabilitation with early range of motion (risk ratio $0.60,0.26$ to $1.37 ; p=0.23 ; I^{2}=0 \%$ ) [45]. No difference in effect estimates was seen between randomized controlled trials and observational studies [45]. Beneficial impact of early dynamic functional rehabilitation has been proven only by both early weightbearing and ankle motion exercises [48]. The results were not superior to immobilization if solely ROM was performed [48].

Weightbearing and ankle motion exercises could have but some detrimental effect, as it has been found in the study from Eliasson et al. that ruptured Achilles tendon (AT) elongates for 6 months after surgical repair regardless of early or late weightbearing in combination with ankle mobilization [49]. Mortensen et al. and 
Kangas et al. showed separation of the tendon ends during the postoperative period [17, 50]. Lee et al. and Clanton et al. warned in their studies about gapping in cycling loading, simulating early postoperative forces after AT repair, what might cause tendon elongation [51, 52]. Weakness of plantar flexion strength, together with deficit in heel-rise test in patients with ATR could therefore be explained with tendon elongation [53-55]. Restoration of the original length and minimizing tendon elongation of the repaired AT should thus be important treatment goals, when aiming for full return of function.

Percutaneous methods have been criticized to be biomechanically weaker in comparison to open repair [6, 51 , 56-58]. On the basis of the results of their study Lee et al. even stated, it would not be advisable to start an early range of motion protocol with immediate weightbearing for patients repaired with the studied percutaneous technique simulating the Achillon system, placing 3 horizontal sutures onto each side of the disrupted AT [51]. Biomechanical studies with static and dynamic loading [59] demonstrated that a modified percutaneous Achilles tendon repair under local anesthesia $[21,60]$ provided almost double the repair strength in comparison to $\mathrm{Ma}$ and Griffiths percutaneous technique [20] and superior strength to other percutaneous and semi-open methods using a Kessler or Bunnell type of repair, and comparable even to some open methods $[51,59,61-74]$. Stronger repair could raise more confidence in early weightbearing and ankle motion exercises with potential lower risk for tendon elongation and lower incidence of complication rate. The main purpose of the presented study was thus to compare the results in patients with an acute ATR after using a stronger, modified percutaneous repair and two ways of postoperative regimen - rigid immobilization or early dynamic functional rehabilitation.

\section{Methods}

Between 2001 and 2004, all the consecutive patients with the ATR treated in the University Clinical Center, who met the below mentioned inclusion criteria and agreed to take a part in this study (approved by the national ethics committee), were randomized after percutaneous suturing under local anesthesia in two groups - based on the day of Team $A$ on service in the functional bracing group (FG) or based on the day of Team $B$ in the group who wore rigid immobilization (IG). There were 8 surgeons altogether operating on patients -4 in each group. The inclusion criteria were: 1 ) patients 18 years of age or older; 2 ) a rupture that occurred no more than 7 days before the operating procedure; 3 ) closed, complete ATR; 4 ) a rupture that occurred in the tendinous portion (2-8 cm proximal to the insertion); 5 ) informed consent; 6 ) no previous operative procedures or history of partial or complete rupture of the involved tendon; 7) no previous local, oral or parenteral therapy that might have weakened the tendon (for instance local infiltration of anesthetics or steroids in the AT region, oral or parenteral immunosuppressive therapy in patients with transplanted organs or immune diseases etc.).

The diagnosis was based on the presented clinical criteria with palpable gap in the tendon, positive Thompson's test $[75,76]$ and inability of the patients to raise on their toes or heel. The diagnosis was routinely checked by ultrasonography and in any case of doubt MRI was available.

All the patients were operated on the same day as they came in the centre, in an outpatient way, with the use of modified percutaneous repair under local anesthesia according to the brief description with photos and drawings in the cited literature $[21,30,60]$. The operation was performed with the patient prone and with the 
injured foot in approximately $25^{\circ}$ plantar flexion (PF), without a tourniquet. No antibiotic or antithrombotic prophylaxis was given.

Before starting, the rupture and location of the diastasis (gap) was localized. After that, proximally and distally (about 4 to $5 \mathrm{~cm}$ ) around the palpated gap, the cutis, subcutis and peritendineum were infiltrated with about $20 \mathrm{ml}$ of $1 \%$ lidocaine through eight puncture holes, which were later used for needle entry and enlarged with scalpel blade No.11. No other medications, nerve blocks or other types of anesthetics or analgetics were given. Special attention was paid to the lateral side, particularly proximally, where nervus suralis lies in the vicinity and crosses the AT (according to the literature from 8.7 to $12.4 \mathrm{~cm}$ proximally to its insertion [77] or 5.7 to $15.5 \mathrm{~cm}$ proximal to the lateral malleolus [78]. Each patient was warned to report if any changes or sore pain was felt in the nervus suralis area during the puncture or infiltration. In that case, the puncture site was changed for about 0.5-1 cm towards the middle (the inner side). The tendon was then repaired with the modified repair configuration using Vicryl (polyglactin) No.2 (Ethicon, Inc., a division of Johnson\&Johnson, Sommerville, New Jersey, USA) [21, 30, 60]. The procedure was started and finished medially and distally. First, the suture on the long, semi-curved needle was transversely passed through the tendon and then cross (diagonal) suture was done. At every site of the first needle entrance or exit, the incision was widened in longitudinal direction by pushing the scalpel blade (No.11) on the thrust-in needle to enable the surgeon to sink the thread subcutaneously (on the paratenon) when proceeding the suture through the same hole (a small haemostat can also be used to widen the hole and enable sinking of the thread). The thread was then led longitudinally, subcutaneously and extratendineously and the next cross through the tendon in the return direction towards AT insertion, was done proximally. After that, both ends were led through the third and second hole, longitudinally, subcutaneously and extratendineously to distally and pulled symmetrically back with careful tension and with the foot in maximal plantar flexion, until both ends of the torn AT were completely approximated and the defect was no longer palpable. After approximating the torn AT ends, as verified by the ultrasonography (transducer was simply put in the sterile glove and sterile lidocaine as it's used for urinary catheterization, was used as media), the lateral end of the thread was passed medially (both ends of the thread must be held tightened at that time), where, after final tightening, the suture was tied and the knots were sunk (buried) subcutaneously through the previously widened second medial stab wound distally (Fig. 1). At the end only 8 small stab wounds and the folds of skin that later completely disappeared, was seen on the surface. Small stab wounds can be closed with very fine suture, but this was not routinely done.

After the procedure a sterile dressing and cast were applied with the foot in $25^{\circ}$ of PF. Patients were allowed to walk with crutches in a toe-touch technique. Initial reevaluation and dressing was performed 2 days postoperatively when a long stockinette (3M, St. Paul, Minnesota, USA)(Fig. 2) was dorsally covered with the splint made of several folded layers of Softcast (3M, St. Paul, MN, USA) with the foot in $25^{\circ}$ PF (Fig. 3). In patients in FG a splint was fixed with a folded stockinette or a simple bandage, what enabled patients to perform PF and prevented dorsal flexion (DF) (Fig. 4). In patients in IG additional two circular layers of Softcast were applied, what produced rigid splint and prevented DF as well as PF of the foot (Fig. 5).

Patients in both groups used crutches for assistance, and careful weightbearing of 5 to $10 \mathrm{~kg}$ was allowed. They were encouraged to perform range-of-motion (ROM) exercises as much as their immobilization allowed. After 3 weeks immobilization in the IG was changed to the rigid splint in neutral position of the foot, whether in the FG immobilization remained the same. Patients in both groups were allowed to start with weightbearing as 
much as tolerated (until pain was felt). If they had no pain, they were allowed to walk even without crutches. Bilateral seated exercises with less and controlled weight-bearing force in comparison to walking and thus resulting in less AT loading, were enhanced in both groups after a week, with progressive loading as much as tolerated in next weeks, till the full ROM was achieved. Softcast (functional) immobilization in the FG routinely softened with weightbearing, so there was no need to exchange this type of immobilization to achieve neutral position of the foot and this was also a way of controlling patients about weightbearing.

After 6 weeks, all immobilization was removed, and patients in both groups started with the rehabilitation according to the same protocol (learned with physiotherapists). They were allowed to walk without crutches, with progressively increasing weightbearing (till tolerable pain) and ROM exercises with careful increasing of DF (till 8 weeks in the sitting position and if possible, in water). Special attention was given to correct any antalgic gait pattern. No additional heel pad or cushion or special shoes were recommended. Patients were encouraged to perform as much as possible exercises in whirlpool, where full weightbearing was allowed. Stretching exercises and squats with lifted heel were allowed after 8 weeks with careful increasing of the load. Raising on toes or heels with the operated leg only was allowed 12 weeks after the operation. Limited sports activities were individually allowed after three months with recommended full loading 6 months after operation (indeed, many patients started with them earlier, including professional athletes).

Patients were followed up regularly at 3 and 6 weeks postoperatively and then at 2, 3 and 6 months. After that they were individually scheduled according to their rehabilitation progress or complication and followed up for 3 years.

Clinical outcome between both groups was assessed using the ankle-hindfoot scale of the rating system developed by the American Foot and Ankle Society (AOFAS hindfoot-ankle score [79-81]. We evaluated also patients' return to the previous activity level, presence of any associated complaints and subjective assessment (it was scored as good, fair or poor).

Objective factors specific to repair of an ATR were also examined [1, 5, 26, 82]. Complications were divided into 2 groups: major and minor complications [2-4]. We measured the thickness of the tendon at its widest diameter in comparison to the noninjured tendon. Thickness of $<1 \mathrm{~cm}$ in diameter was assessed as mild, $<$ $2 \mathrm{~cm}$ as moderate and $>2 \mathrm{~cm}$ as great. The neutral zero method [83] was used for assessment of ankle motion, with the maximum DF considered to be $20^{\circ}$ and PF to be $50^{\circ}$. Beside measurement of active ankle motion, possible difference in DF in patients was assessed also by performing squat, using two chairs aside and placing some weight on the hands. First deep squat was performed with the raised heels, after what patients were leaning back till the whole sole was on the floor during squat. In this position difference in DF of the foot was able to be detected (loss or increase of DF). PF was passively assessed with patient lying prone (or in younger patients kneeling) and observing any difference in the position of the fully stretched feet on the flat board (loss or increase of PF). Strength and endurance were tested clinically, using the standing heel-rise test, to require 25 repetitions for a grade of normal [84]. Patients were instructed to stand straight and to rise and lower on the balls of their feet in rhythm of 1 heel-rise every 2 seconds. They were asked first to raise 25 times on their toes with both legs simultaneously (Test 1), then with the noninjured leg followed by the injured leg (Test 2). They could balance with their hand at the edge of the table, but were not allowed to place weight on the hand. The results are presented for each group separately. 
All measurements and assessments were done by the authors (AC, RK) and cross-checked with the surgeons, who performed the operation, at the final exam.

The results were analyzed statistically with the t-test for numerical parameters and Fisher exact test for attributive parameters using IBM SPSS 24.0 statistical software (IBM Inc., Armonk, New York); $p$ value less than 0.05 was considered statistically significant.

\section{Results}

There were 31 patients (32 ruptures, as one man sustained a rupture of the contralateral tendon 1 year apart) in the FG and 30 patients in the IG who met the above mentioned inclusion criteria (all of them agreed to participate in the study). The procedures were well tolerated, with no pain and complication during them, in all patients, regardless of the used method. There were no allergic reactions to lidocaine, or problems with the suture breakdown.

Final assessment was possible in all 61 patients. There were $56(91.80 \%)$ men and 5 (8.19\%) women (ratio 11.2:1), with a mean age of 42.06 years (range 29-71, SD \pm 11.56$)$, with $34(55.73 \%)$ left-sided and 28 (45.90\%) right-sided ruptures. Characteristics of comparable groups are presented in Table 1. 
Table 1

Data of patients

\begin{tabular}{|lll|}
\hline & FG (functional) & IG (rigid) \\
\hline Number of patients & 31 & 30 \\
\hline Number of patients with both side ruptures & $1(3.22 \%)$ & $0(0 \%)$ \\
\hline Number of procedures & 32 & 30 \\
\hline Gender- male & $28(90.32 \%)$ & $28(93.33 \%)$ \\
\hline - female & $3(9.676 \%)$ & $2(6.66 \%)$ \\
\hline Side- left & $17(53.12 \%)$ & $17(56.66 \%)$ \\
\hline - right & $15(46.87 \%)$ & $13(43.33 \%)$ \\
\hline Mean age (in years)(SD) & $41.93(12.29)$ & $42.20(10.53)$ \\
\hline Age of the youngest and oldest patient (in years) & $29 / 71$ & $29 / 57$ \\
\hline Injured during sports activities (number) & $20(62.50 \%)$ & $18(60.00 \%)$ \\
\hline High-calibre athletes & $1(3.22 \%)$ & $1(3.33 \%)$ \\
\hline Type of sports-activities: soccer & $9(45.00 \%)$ & $9(50.00 \%)$ \\
\hline basketball & $4(26.31 \%)$ & $4(22.22 \%)$ \\
\hline tennis & $2(10.52 \%)$ & $1(5.55 \%)$ \\
\hline volleyball & $1(5.26 \%)$ & $1(5.55 \%)$ \\
\hline handball & $1(5.26 \%)$ & $0(0 \%)$ \\
\hline gymnastics & $0(0 \%)$ & $1(5.55 \%)$ \\
\hline track\&field & $1(5.26 \%)$ & $1(5.55 \%)$ \\
\hline other sports & $2(10.52 \%)$ & $1(5.55 \%)$ \\
\hline
\end{tabular}

Complications are listed in Table 2. There were no re-ruptures in the FG and 1 patient in the IG sustained a rerupture, 7 weeks after the procedure, during the uncontrolled, full loading during a fall on the slippery floor in the swimming pool. This patient was reoperated in an open way with overlap augmentation in spinal anesthesia, with no later complications and complete return to all his previous activities, with some minor complaints, during high demanding activities. There were no other major complications in both groups. 
Table 2

Complications in both groups

\begin{tabular}{|c|c|c|c|}
\hline MAJOR COMPLICATIONS & FG & IG & $p$ \\
\hline Rerupture & 0 & $1(3.33 \%)$ & $p=0.48$ \\
\hline Second rerupture & 0 & 0 & \\
\hline Permanent equinus position of the foot & 0 & 0 & \\
\hline Extreme lengthening of the Achilles tendon & 0 & 0 & \\
\hline Deep infection & 0 & 0 & \\
\hline Chronic fistula & 0 & 0 & \\
\hline Necrosis of the skin & 0 & 0 & \\
\hline Deep vein thrombosis & 0 & 0 & \\
\hline Embolism & 0 & 0 & \\
\hline Death & 0 & 0 & \\
\hline TOGETHER & 0 & $1(3.33 \%)$ & $p=0.48$ \\
\hline \multicolumn{4}{|l|}{ MINOR COMPLICATIONS } \\
\hline Superficial infection & 0 & 0 & \\
\hline Wound hematoma & 0 & 0 & \\
\hline Delayed wound healing & 0 & 0 & \\
\hline Adhesion of the scar & 0 & 0 & \\
\hline Disturbances of sensibility & $2(6.25 \%)$ & $1(3.33 \%)$ & $p=1$ \\
\hline Suture granuloma & 0 & $1(3.33 \%)$ & $p=0.48$ \\
\hline Suture rupture & 0 & 0 & \\
\hline TOGETHER & $2(6.25 \%)$ & $2(6.66 \%)$ & $p=1$ \\
\hline ALL COMPLICATIONS TOGETHER & $2(6.25 \%)$ & $3(10.00 \%)$ & $p=0.66$ \\
\hline OVERALL COMPLICATIONS (MAJOR) & $1(1.61 \%)$ & & \\
\hline OVERALL COMPLICATIONS (MINOR) & $4(6.45 \%)$ & & \\
\hline OVERALL COMPLICATIONS TOGETHER & $5(8.06 \%)$ & & \\
\hline
\end{tabular}

Three patients (4.83\%), 2 in FG and 1 in IG, claimed disturbances in the nervus suralis distributed area. Problems have started within 3 weeks after the operation, when in 2 of these patients significant fibrous thickness at the operative site could be palpated. These patients were encouraged in taking non-steroid antiinflammatory drugs and B-complex vitamins together with additional massage with emollient creams and 
friction massage during rehabilitation. The troubles resolved in all patients without any operative procedures after a period of 4 to 10 months. There was 1 patient (3.33\%) in IG with suture extrusion problem (in fact the surgeon did not burry the knot properly), which resolved with regular dressings and removal of the remained part of a knot within a week. There were $8.06 \%$ of altogether complications (in 5 out of 62 procedures), with $6.25 \%$ altogether complications in FG (in 2 out of 32 procedures) and $10.00 \%$ in IG (in 3 out of 30 procedures). Comparison of the results between both groups revealed no statistically significant difference in AOFAS score (96.87 (range 86-100) in the FG versus 95.96 (range 87-100) in the IG; $p=0.38$ ).

Objective factors specific to repair of an ATR are presented in Table 3. 
Table 3

Results of additional examined factors after AT repair

\begin{tabular}{|c|c|c|c|c|}
\hline & & FG & IG & $p$ \\
\hline Test 1 (raising on tiptoe (RTT) $-25 x$ ) & (with both legs) & all & all & \\
\hline Test 2 (RTT - operated leg - 25x) & (symmetrically) & $23(71.87 \%)$ & $22(73.33 \%)$ & $p=1$ \\
\hline (RTT - operated leg - 25x) & (weakness) & $6(18.75 \%)$ & $5(16.66 \%)$ & $p=1$ \\
\hline NOT PASSED & (with operated leg) & $3(9.37 \%)$ & $3(10.00 \%)$ & $p=1$ \\
\hline NOT PASSED & (with noninjured leg) & $2(6.45 \%)$ & $2(6.66 \%)$ & $p=1$ \\
\hline Diameter of tendon & $<10 \mathrm{~mm}$ & $15(46.87 \%)$ & $15(50.00 \%)$ & $p=1$ \\
\hline \multirow[t]{2}{*}{ (difference) } & $10-20 \mathrm{~mm}$ & $11(34.37 \%)$ & $10(33.33 \%)$ & $p=1$ \\
\hline & $>20 \mathrm{~mm}$ & $6(18.75 \%)$ & $5(16.66 \%)$ & $p=1$ \\
\hline Dorsal flexion & (symmetrical) $\left(20^{\circ}\right)$ & $30(93.75 \%)$ & $28(93.33 \%)$ & $p=1$ \\
\hline \multirow[t]{2}{*}{ (loss of dorsal flexion) } & $\left(5^{\circ}-10^{\circ}\right)$ & $2(6.25 \%)$ & $2(6.66 \%)$ & $p=1$ \\
\hline & $\left(>10^{\circ}\right)$ & 0 & 0 & \\
\hline (increase of dorsal flexion) & $\left(>5^{\circ}\right)$ & 0 & 0 & \\
\hline Plantar flexion & (symmetrical) $\left(50^{\circ}\right)$ & $29(90.62 \%)$ & $27(90.00 \%)$ & $p=1$ \\
\hline \multirow[t]{2}{*}{ (loss of plantar flexion) } & $\left(5^{\circ}-10^{\circ}\right)$ & $3(9.37 \%)$ & $3(10.00 \%)$ & $p=1$ \\
\hline & $\left(>10^{\circ}\right)$ & 0 & 0 & \\
\hline (increase of plantar flexion) & $\left(>5^{\circ}\right)$ & 0 & 0 & \\
\hline \multirow[t]{3}{*}{ Return to previous activities } & (no limitation) & 25 (80.64\%) & $24(80.00 \%)$ & $p=1$ \\
\hline & (with complaints) & $6(19.35 \%)$ & $6(20.00 \%)$ & $p=1$ \\
\hline & (not possible) & 0 & 0 & \\
\hline \multirow[t]{3}{*}{ Return to sports activities } & (no limitation) & $17(85.00 \%)$ & $16(84.21 \%)$ & $p=1$ \\
\hline & (with limitations) & $3(15.00 \%)$ & $3(15.78 \%)$ & $p=1$ \\
\hline & (not possible) & 0 & 0 & \\
\hline \multirow[t]{3}{*}{ Subjective assessment } & (good) & $28(90.32 \%)$ & $26(86.66 \%)$ & $p=0.707$ \\
\hline & (fair) & $3(9.67 \%)$ & $4(13.33 \%)$ & $p=0.707$ \\
\hline & (poor) & 0 & 0 & \\
\hline
\end{tabular}

Patients in the IG had slightly lower diameter of the healed AT in comparison to the patients in the FG. Patients in the FG were subjectively slightly more satisfied with the treatment in comparison to the patients in IG. There were no statistically significant differences between both groups according to any analyzed factor in Table 3 , 
including return to previous activities and specifically to sports activities in patients who sustained ATR during them. There were no complications with a full return to all activities (in 4 and 6 months) in both high-calibre athletes.

We assessed also functional results between both groups specifically through the observational time period that are presented in Table 4 (bold numbers in the table represent time period since the final condition was achieved). Patients in FG showed earlier correct gait pattern with no limping and achieved earlier final ROM and comparable muscular strength to the non-operated leg, but the final results were comparable in both groups, with no statistically significant differences.

Table 4

Functional results during follow-up period

\begin{tabular}{|c|c|c|c|c|c|}
\hline & $\begin{array}{l}2 \\
\text { months } \\
\mathrm{FG}(\%) / \\
\mathrm{IG}(\%)\end{array}$ & $\begin{array}{l}3 \text { months } \\
F G(\%) / I G(\%)\end{array}$ & $\begin{array}{l}6 \text { months } \\
\mathrm{FG}(\%) / \mathrm{IG}(\%)\end{array}$ & $\begin{array}{l}12 \text { months } \\
\text { FG(\%) / IG(\%) }\end{array}$ & $\begin{array}{l}\text { Final } \\
F G(\%) / I G(\%)\end{array}$ \\
\hline Limping & $\begin{array}{l}4(12.5) \\
/ \\
6(20,0) \\
p= \\
0.502\end{array}$ & $\begin{array}{l}0(0) / 3(10,0) \\
p=0.107\end{array}$ & $0(0) / 0(0,0)$ & $0(0) / 0(0,0)$ & $0(0) / 0(0,0)$ \\
\hline $\begin{array}{l}\text { ROM } \\
\text { (loss / PF) }\end{array}$ & $\begin{array}{l}5(15.6) \\
/ \\
7(23.3) \\
p= \\
0.528\end{array}$ & $\begin{array}{l}4(12.5) / 5(16.6) \\
p=0.728\end{array}$ & $\begin{array}{l}3(9.3) / 3(10,0) p \\
=1\end{array}$ & $\begin{array}{l}3(9.3) / 3(10,0) \\
p=1\end{array}$ & $\begin{array}{l}3(9.3) / 3(10,0) p \\
=1\end{array}$ \\
\hline $\begin{array}{l}\text { ROM } \\
\text { (loss / DF) }\end{array}$ & $\begin{array}{l}4(12.5) \\
/ \\
6(20,0) \\
p= \\
0.502\end{array}$ & $\begin{array}{l}4(12.5) / 6(20,0) \\
p=0.502\end{array}$ & $\begin{array}{l}2(6.2) / 3(10,0) p \\
=0.666\end{array}$ & $\begin{array}{l}2(6.2) / 2(6.6) \\
p=1\end{array}$ & $\begin{array}{l}2(6.2) / 2(6.6) \\
p=1\end{array}$ \\
\hline $\begin{array}{l}\text { Test } 1 \\
\text { (both legs) }\end{array}$ & & $\begin{array}{l}27(84.3) / 21(70,0) \\
p=0.229\end{array}$ & $32(100) / 30(100)$ & $32(100) / 30(100)$ & $32(100) / 30(100)$ \\
\hline $\begin{array}{l}\text { Test } 2 \\
\text { (op leg) }\end{array}$ & & $\begin{array}{l}14(43.7) / 10(33.3) \\
p=0.443\end{array}$ & $\begin{array}{l}16(50.0) / 14(46.6) \\
p=0.805\end{array}$ & $\begin{array}{l}22(68.7) \\
/ 21(70,0) p=1\end{array}$ & $\begin{array}{l}23(71.8) / 22(73.3) \\
p=1\end{array}$ \\
\hline $\begin{array}{l}\text { Test } 2 \\
\text { (weakness) }\end{array}$ & & $\begin{array}{l}10(31.2) / 8(26,6) \\
p=0.783\end{array}$ & $\begin{array}{l}11(34.3) / 12(40,0) \\
p=0.793\end{array}$ & $\begin{array}{l}7(21.8) / 6(20,0) \\
p=1\end{array}$ & $\begin{array}{l}6(18.7) / 5(16.6) \\
p=1\end{array}$ \\
\hline $\begin{array}{l}\text { Test } 2 \text { NOT } \\
\text { (op leg) }\end{array}$ & & $\begin{array}{l}8(25.0) / 12(40.0) \\
p=0.279\end{array}$ & $\begin{array}{l}5(15.6) / 6(20.0) \\
p=0.745\end{array}$ & $\begin{array}{l}3(9.3) / 3(10.0) \\
p=1\end{array}$ & $\begin{array}{l}3(9.3) / 3(10.0) \\
p=1\end{array}$ \\
\hline $\begin{array}{l}\text { Test } 2 \text { NOT } \\
\text { (nonop leg) }\end{array}$ & & $\begin{array}{l}2(6.2) / 2(6.6) \\
p=1\end{array}$ & $\begin{array}{l}2(6.2) / 2(6.6) \\
p=1\end{array}$ & $\begin{array}{l}2(6.2) / 2(6.6) \\
p=1\end{array}$ & $\begin{array}{l}2(6.2) / 2(6.6) \\
p=1\end{array}$ \\
\hline
\end{tabular}


When comparing post-operative final results in patients, there could be found that the final correct gait pattern was achieved within 6 months and final ROM within 12 months. Changes in the muscular strength were noticed up to 3 years after the ATR.

\section{Discussion}

The fundamental goals of treatment of an acute ATR are to restore length and tension of the tendon and thus to optimize a patient's ability to return to the previous level of activity, with as few complications as possible. In complete ATR there always come to the retraction of triceps muscle, resulting in a gap, which is filled in a healing process with fibrous tissue, that is but not as strong as tendon $[30,55,60,85]$. Restoration of the length with a good approximation of the torn ends is believed to have an impact on the low number of re-ruptures in operative treatment $[30,55,60,85]$. In conservative treatment the extent of the fibrous tissue could somehow be influenced by positioning of the foot in PF and with early functional treatment $[5,9-13,85,86]$. Early ankle motion exercises and weightbearing might have an impact on the histologic properties of a healing tendon (tissue arrangement and collagen type) and thus on stiffness, adhesion formation, gapping resistance and (re)rupture strength [85-87]. The proposed mechanism of this is that physiological forces promote gene expression of type I collagen formation during healing and that tension causes the collagen to be deposited and aligned in parallel fashion [88]. The same beneficial effect of faster healing of tendons if they are subjected to loading can be found after operative treatment as well [86, 87]. It has been noted but that disproportionate weakness in end-range plantar flexion, decreased passive stiffness in dorsiflexion and inability to perform a decline heel rise (lower strength) are evident after ATR and repair [89]. Possible causes include anatomical lengthening, increased tendon compliance and insufficient tendon rehabilitation after ATR $[50,89]$ or could be chronic adaptations associated with ATR [85].

Stronger repair with good adaptation of the torn ends could thus be beneficial in any type of repair, including percutaneous repair of the ruptured AT. This type of repair has been criticized to be weaker than open operative repair $[6,51,56-58]$ and that in closed technique the ends cannot be visualized and brought into a good, completely approximated position, with difficulties achieving appropriate length and tension at the repair site $[30,57,58,73]$. Semi-open or minimally invasive (MI) methods of AT repair were thus proposed, many using special (costly) instruments (like Achillon ${ }^{\circledR}$ system (Integra Life Sciences Corporation, Plainsboro, NJ), PARS ${ }^{\text {Tm }}$ system (Arthrex, Naples, FL), Achilles midsubstance Speed Bridge repair variation (Arthrex, Naples, FL)) with several sutures or anchors [23-28,52]. The torn ends in ruptured AT are often friable and uneven and pulling them together to achieve a good approximation has proven difficult $[20,24,25,30,60]$. The majority of the proposed percutaneous techniques enable pulling the torn ends only at one side, what might leave the gap on the opposite side (so called »fish - tail« effect) or causes tearing and cutting a tendon with the thread during stronger pulling in an attempt to reapproximate both sides $[30,60]$. This is why we recommend more »rough« material, like Vicryl instead of for instance more »smooth « PDS ${ }^{\circledR}$ No.2 (polydioxanone) (Ethicon, Inc., a division of Johnson\&Johnson, Sommerville, NJ), with a greater risk of cutting a tendon. In the types of »crossing technique $[90,91]$, interference with the approximation at the site of the rupture, can occur. This results in a potential residual gap that is healed with weaker fibrous tissue and with lengthening of the tendon. The proposed modified technique is one of the first percutaneous methods performed under local anesthesia [21] and at the moment the only closed one that enables approximation of torn ends by pulling them symmetrically

Page $13 / 33$ 
and simultaneously at both sides, using the principle of »double pulley technique« [30,60]. Despite this technique is more demanding, it enables less force needed to make a good apposition of the torn ends, with less risk of cutting the tendon during pulling and minimizes the pullout forces at the junction of the suturetendon interface [30, 60, 92]. Instead of opening the site of rupture to control the approximation of the torn ends, what is used in mini invasive methods, approximation can be controlled and assisted by ultrasonography $[30,60]$, which we recommend during initial use of the proposed method and until the surgeon is comfortable with the technique and proper pulling strength. It is very important to approximate the torn ends until the defect is no longer palpable and visible by ultrasonography and maximal PF of the foot during reapproximation and tightening probably assists in this maneuver. It seems therefore that in the term of controlling apposition of the ends, there is no real need to open this area or to use arthroscope, particularly if keeping in mind losing biological potential and increasing the risk of infection.

Resistance to elongation together with resistance against gapping and failure under cyclic (repetitive) loading was intensively studied in biomechanical testing of several methods, including open, semi-open (minimally invasive) and percutaneous (closed) types of repair [51, 59, 61-74]. The results of biomechanical (cadaveric) testing of percutaneous and mini-invasive methods are listed in Table 5.

Besides the technique itself, the strength of tendon repair depends on three factors: the holding capacity of the suture material within the tendon (the coefficient of friction); the strength of the knot; and the strength of the suture material itself [73]. More strands and knots with locking type of sutures do have impact on strength of the repair, but also on biological potential of healing (diminished tendon blood supply, additionally if performed in (semi)open way) and possible complication (particularly with the use of non-resorbable thread) like adhesions, suture extrusion and friction within the paratenon with affecting glide, that might end with the need for reoperation [28, 93]. The proposed method showed in biomechanical testing the highest strength among closed percutaneous methods. Semi-open methods with previously cited tendon repair systems showed in some (but not all) biomechanical testing stronger repair in comparison to the proposed method [51, 59, 61-74], but demand special instruments and more (generally 6) sutures (with anchors) and produce higher costs with the potential risks as stated above. The strongest repair in biomechanical testing showed otherwise open repair with Krackow locking loop (582 N) [94], but if instead of No.2 polyblend sutures (Fiberwire, Arthrex, Naples, Fl, USA) No.1 Ethibond suture (Ethicon, Inc., a division of Johnson\&Johnson, Sommerville, New Jersey, USA) was used, the load to failure with the same type of repair was only $147 \mathrm{~N}$ [63] or $161 \mathrm{~N}$ [95]. 
Table 5

Comparison of Achilles tendon repairs ranked by load to failure

\begin{tabular}{|c|c|c|c|c|}
\hline Technique (closed) & Suture material & No. of strands & Load to failure $(N)$ & Author \\
\hline Kessler (type) & 2 - 0 Fiberwire & 2 & 38 & 61 \\
\hline Bunnell (type) & 0 Ticron & 2 & 78 & 62 \\
\hline Bunnell (type) & 1 Ethibond & 2 & 93 & 63 \\
\hline Carmont-Maffulli & 2 Prolene & 4 & 106 & 64 \\
\hline Ma-Griffith & 2 Vicryl & 2 & 111 & 59 \\
\hline Kessler ("Dresden") & 1 PDS & 2 & 137 & 65 \\
\hline Double Kessler (type) & $1-0$ Silk & 4 & 154 & 66 \\
\hline Bone Anchor repair & 1 Panacryl & 4 & 166 & 67 \\
\hline Kessler ("Dresden") & 2 Mersilene & 2 & 167 & 68 \\
\hline Bone Anchor repair & 1 PDS-II & 4 & 185 & 67 \\
\hline Calcaneal Tunnel & 1 Panacryl & 4 & 186 & 67 \\
\hline Calcaneal Tunnel & 1 PDS-II & 4 & 195 & 67 \\
\hline Modified (Cretnik) & 2 Vicryl & 4 & 214 & 59 \\
\hline Technique (semi-open (MI)) & Suture material & No. of strands & Load to failure $(\mathrm{N})$ & Author \\
\hline Kessler (type) & 1 Ethibond & 2 & 85 & 63 \\
\hline Achillon & 2 Ethibond & 6 & 100 & 51 \\
\hline Achillon & 2 Prolene & 6 & 104 & 64 \\
\hline Kessler (type) & 2 Ticron & 2 & 123 & 69 \\
\hline Kessler ("Dresden" (modif.)) & 1 PDS & 2 & 137 & 65 \\
\hline Bunnell (type)("Majewski") & 1 PDS & 2 & 139 & 65 \\
\hline Achillon & 2 Ticron & 6 & 153 & 69 \\
\hline Double Kessler ("Webb-Bannister") & 2 Mersilene & 4 & 166 & 68 \\
\hline Kessler (type) & $0.7 \mathrm{~mm}$ PDS (cord) & 2 & 193 & 70 \\
\hline PARS & 2 FiberWire & 6 (sutures) & 206 & 71 \\
\hline Bunnell (type) & $0.7 \mathrm{~mm}$ PDS (cord) & 2 & 255 & 70 \\
\hline Achillon & 2 FiberWire & 6 & 299 & 72 \\
\hline Achillon & 1 Ethibond & 6 & 342 & 73 \\
\hline PARS & 2 FiberWire & 6 (sutures) & 353 & 74 \\
\hline
\end{tabular}




\begin{tabular}{|lllll|}
\hline Technique (closed) & Suture material & No. of strands & Load to failure (N) & Author \\
\hline PARS ("Speed Bridge") & 2 FiberWire & 6 (anchors) & 385 & 71 \\
\hline PARS ("Speed Bridge") & 2 FiberWire & 6 (anchors) & 385 & 72 \\
\hline
\end{tabular}

Stronger repair could support more confidence and resistance against widening of the gap during the functional rehabilitation and healing with elongation of the ruptured AT [51-54,59]. These all might be beneficial also in reducing the incidence of re-rupture. Percutaneous repair is associated with a re-rupture rate from $2.6-16.7 \%[22,26,30,39,56-58,96,97]$, although some papers about percutaneous repair without this complication can be found $[20,21,25,28]$. Hsu et al. reported in their retrospective cohort study no re-rupture in treatment of 101 patients with PARS ${ }^{\text {'m }}$ system and 169 patients in an open way [28]. Bartel et al. reported in the systematic review of incidence of complications after Achillon ${ }^{\circledR}$ system in 8 eligible of 33 studies the re-rupture incidence of $3.2 \%$ (in 8 of 253 patients) [98]. Yang et al. found in their meta-analysis of 5 randomized controlled trials and 7 retrospective cohort studies about outcomes and complications of percutaneous versus open repair of acute ATR involving 815 patients, 13 (3.1\%) out of 424 percutaneously treated patients who experienced re-rupture [99]. In our series there was 1 patient (1.61\%) in IG out of 62 procedures who suffered a re-rupture. As none of the patients in the FG experienced a re-rupture, the proposed modified method showed in our study strong and reliable enough for early functional treatment and with lower re-rupture rate even in comparison to the results in meta-analyses for the open operative reconstruction $(1.4-4.4 \%)[35,38-41,43,99$, 100].

Re-rupture and (severe) wound infection are the most important complications with lasting negative effect on outcome $[30,39,40,43,98,101-103]$. Open surgery around the AT has a wound-related complication rate of between $8.2 \%$ and $34.1 \%,[11,39,102]$, of which at least half are due to infection [103]. Meta-analyses in open procedures revealed deep infection rate of $2.3 \%[40,43]$. Reports of infection rate with the use of percutaneous and semi-open methods differ quite a lot from $0-13.3 \%[20,28,30,39,57,60,96,104]$. Bartel et al. reported in the systematic review of incidence of complications after Achillon ${ }^{\circledR}$ system the infection rate of $0.8 \%$ (in 2 of 253 patients) [98]. Saxena et al. reported that the overall incidence of wound infections in surgeries pertaining to the AT was 3.1\% (in 7 of 219 patients) [103]. Yang et al. found in their meta-analysis 9 eligible studies revealing the occurrence rate of deep infection $0.6 \%$ with percutaneous treatment and $3.6 \%$ with open treatment in total [99]. A subgroup analysis of only 5 RCTs showed no significant difference between these two groups ( $\mathrm{RR}=0.42,95 \% \mathrm{Cl} 0.11$ to $0.96, p=0.99 ; \mathrm{I}^{2}=0 \%$ [99]. Grassi et al. found in their meta-analysis of 8 randomized controlled trials with 182 patients treated with minimally invasive surgery and 176 treated with open repair, significantly decreased risk ratio (RR) of 0.15 (95\% confidence interval $[\mathrm{Cl}]=0.05$ to $0.46, p=$ 0.0009) for wound infection after minimally invasive surgery [105]. When deep and superficial infections were analyzed separately, only the superficial infections remained significantly decreased in the minimally invasive surgery group after both random and fixed-effect meta-analysis with a relative risk reduction (RRR) of $83 \%$ [105]. In our series no patient received antibiotic prophylaxis, including patients with diabetes, corticosteroid use and smoking, that were found together with age as major risk factors for infection $[98,102,103]$ and no infection or problems with wound healing occurred.

Percutaneous methods, particularly closed (blind) suturing, were criticized about high rate of sural nerve injury $[6,24,56,58]$. Semi-open methods were introduced to reduce the problems with sural nerve entrapment as well 
as for the control of approximation of torn ends [23, 24, 26-28]. Indeed, opening the site of the rupture and introducing different types of (costly) devices or surgical instruments (forceps) can reduce the occurrence of sural nerve problems, but raises the same concerns as with the open fractures, with losing (biological) healing potential (mediators and molecules in hematoma) and increasing risk of infection and wound dehiscence [28, $30,60,98,102]$. There were attempts to solve these problems with biological enhancement, such as adding platelet rich plasma (PRP), but there is still lack of evidence to support this solution [104]. Some authors reported complete elimination of the sural nerve problems using semi-open methods [22, 26, 28]. According to meta-analysis, this problem occurs in $0.78 \%$ in conservative treatment [40] as well as in open operative repair in up to $8.76 \%$ of cases, despite being able to preserve the sural nerve through cautious operative technique [40, 106]. Assal et al. reported no sural problems in the first paper using Achillon ${ }^{\circledR}$ (semi-open) system [26]. Bartel et al. reported but in the systematic review of incidence of complications after using the same system 1,2\% (in 3 of 253 patients) sural nerve injuries [98]. Aibinder et al. found in their cadaveric study using the Achillon device that 8 of the 54 needle passes (14.8\%) directly pierced the substance of the sural nerve, what could be diminished with external rotation of device [107]. Majewski et al. proposed additional stab incisions on the lateral site to expose the sural nerve to avoid hitting it during repair, what otherwise occurred in $18 \%$ of their 84 percutaneously treated patients [108]. In our first series [21] with the use of the proposed method in 36 patients there were no problems with sural nerve entrapment. In our longer-term study [30] from 1991 to 1997, there were $6(4.47 \%)$ out of 134 cases with disturbances of sensibility, that spontaneously resolved in 2 to 10 months without any surgical intervention needed. In this series in $3(4.83 \%)$ of 62 cases problems (paresthesias) with sural nerve disturbances were noted. Interestingly no-one claimed about this problem immediately after the surgery (but after 1 to 3 weeks) and no-one experienced anesthesia in the area of the sural nerve. If operating under local anesthesia, patients should be warned to immediately report if any changes in sensation occur within the area of anesthetic infiltration, particularly at the lateral site, where sural nerve crosses lateral border of the tendon ( 8.7 to $12.4 \mathrm{~cm}$ proximally to the AT insertion [77]) and where the position of the entry site of the thread shouldn't cross lateral edge of a tendon. In our series we used resorbable thread (Vicryl No.2) and there was no need to perform any surgical revision or release in patients with sural nerve problems, as they all spontaneously resolved. Spontaneous biodegradation of resorbable thread and thus probably relieving the sural nerve problems, which might be entrapped in the scar formation in the first weeks in the healing process, what could explain also occurrence of this problem in conservatively treated patients [30,41,60], might benefit to the procedures like stretching and friction massage during physiotherapy after healing.

Functional treatment with early ankle motion and early weightbearing could diminish negative effect of immobilization and thus risk for deep venous thrombosis (DVT) and venous thromboembolism (VTE). There is but no clear consensus about incidence of VTE and prophylaxis in patients after ATR [11, 109-111]. The reported overall incidence for VTE in foot and ankle surgery with and without chemoprophylaxis was $0.6 \%$ (95\% $\mathrm{Cl} 0.4-0.8 \%)$ and $1 \%(95 \% \mathrm{Cl} 0.2-0.7 \%)$ [109]. Calder et al. found greater risk of VTE in patients with ATR with a clinical incidence of $7 \%(95 \% \mathrm{Cl} 5.5-8.5 \%)$ [110]. Aufwerber et al. reported about 35 (37\%) of 94 patients DVT in the early functional group with full weightbearing and ankle motion in orthosis and $14(29 \%)$ of 49 patients in control group with 2 weeks of unloading in plaster cast followed by 4 weeks in weightbearing in orthosis, 6 weeks after ATR [111]. Patel with co-workers reported but lower overall rates in patients with ATR for DVT of $0.43 \%$ (5 of 1172) and for pulmonary embolism of $0.34 \%$ (in 4 of 1172 patients) [109]. The American 
College of Chest Physicians' (ACCP) most recent review recommends against chemical prophylaxis in lower leg injuries requiring immobilization [112]. It is but necessary that patient-specific risk factors for VTE should be used to assess patients individually $[110,112]$. In our series with no routine thromboprophylaxis in any of groups and with no patients on routine anticoagulant therapy, there was no case of DVT and no case of pulmonary embolism. As the operation was performed in local anesthesia with infiltration, patients who might have been on peroral anticoagulants should be switched before operation to low molecular weight heparin $(\mathrm{LMWH})$ and reverted to peroral anticoagulants in the next days after the surgery.

Wu et al. found in a systematic review and network meta-analysis of 2060 patients with ATR in 29 randomized controlled trials the mean incidence of overall major complications from all managements $9.13 \%$ (median, $6.67 \%$ ) and $8.47 \%$ in the group of minimally invasive surgery and accelerated rehabilitation [46]. The mean incidence rates of rerupture, deep infection and DVT from all managements were $5 \%, 1.50 \%$, and $2.67 \%$, respectively [46]. The results in our study, with the use of modified AT repair under local anesthesia and functional treatment, showed lower incidence of any of described complications $(6.2 \%$ of overall complications, with no re-ruptures, no infections and no DVT).

Despite studies support its efficacy in any type of treatment of ATR [5, 9-11], early functional rehabilitation has lacked a standard definition and interventions and outcome measures are highly variable [113]. There's also limited evidence for optimized rehabilitation regimen and guidelines, particularly for the first 6 weeks after ATR $[113,114]$. As it is associated with a lower complication rate and achieves superior and more rapid functional recovery than conventional immobilization, it was proposed that early ankle motion combined with early weightbearing should become the standard rehabilitation protocol after surgical treatment of acute ATRs [48, 113]. This concept should be therefore accepted also in percutaneous (minimally invasive) treatment. It should be kept in mind that during early functional rehabilitation repaired ATs are exposed to a lot of (cyclic) loading, so gapping and tendon lengthening could occur with too aggressive burdening. A very simple clinical advice could be therefore proposed to patients, to perform the extent of ROM and load during weightbearing until pain is felt. It means but on the other side that patients should be compliant and motivated in rehabilitation process what could be generally very well seen in (professional) sportsmen, who are sometimes even too eager in exercising with even too much loading of the operated tendon, what increases the risk of re-rupture and tendon elongation. Patients in our study in both groups started immediately after the procedure with toe-touch technique of walking with crutches and within the first week with partial weightbearing about $5 \mathrm{~kg}$. Within the first 3 weeks after the procedure they were allowed to increase partial weightbearing up to $15 \mathrm{~kg}$ and after 3 weeks to put weight as much as tolerated (until pain). Patients in FG were enhanced to start immediately with ROM exercises as much as their immobilization allowed, which was designed in the way that enabled immediately PF, but restricted DF. Immobilization that was made of stockinette and one package of softcast in FG and 2 packages in IG (to be rigid) was not only very cheap, but also comfortable to wear and simple to take off and on in patients in FG, who were allowed to do this after a week and even to perform PF and DF in water without orthosis until pain was felt. Bilateral seated exercises were allowed in both groups after 3 weeks, when softcast was changed into neutral position of the foot in IG. Putting the weight on the foot produced softening of the dorsal splint in patients in FG and enabled gradual increasing of DF till neutral position, what served also as an effective control of weightbearing in patients in this group. There was no breakage of immobilization in any patient within 6 weeks until it was finally removed in both groups. There was no increase in DF or PF at the end in any of the patient and there were 2 patients in both groups who loss DF for up to $10^{\circ}$ and 3 patients in 
both groups with loss of PF up to $10^{\circ}$. Increased DF and loss of PF could reflect increased length of AT, but all the patients in our series with diminished PF at the final examination had also diminished DF, what could probably reflect more a stiffness of ankle joint and/or capsular adhesions than a tendon elongation. Patients in FG reached earlier correct pattern of gait without limping, earlier better strength and final ROM and were more satisfied with treatment, but the final results according to ROM, strength, return to previous and sports activities and subjective assessment were comparable in both groups with no statistically significant differences.

Many different scoring systems have been proposed for assessment of clinical outcome after ATR treatment but none has been universally accepted $[4-6,26,79-82,108,115,116]$. There are many reasons for that, including subjective parameters in some scales and high technical demands and costs in others $[11,60,80$, 82]. AOFAS hindfoot-ankle score [79] is one of the attempts to solve this dilemma, showing good reliability and validity compared with other scoring systems, despite still including some subjective determinations and parameters less relevant to ATR treatment [80, 81]. Some adapted scores such as the Achilles tendon Total Rupture Score [115] and Self Reported Foot and Ankle Score (SEFAS) [116] had not been developed and reported when our randomized prospective study started, so we used AOFAS hindfoot-ankle score, which has been used in many other studies $[22,26,33,117]$. The average AOFAS hindfoot-ankle scores of 96.87 in FG and 95.96 in IG $(p>0.005)$ showed no statistically significant differences between both groups and are comparable to the results of other percutaneous and minimally invasive methods $[22,26,33,117]$.

One of valuable objective parameters in assessment of tendon strength after the treatment is isokinetic testing $[5,82,118-121]$. As this is associated with many, particularly logistic, technical and financial factors, this testing is not universally accepted in assessment scores [5, 6, 30, 82]. Isokinetic studies in other studies showed no statistical difference in strength, power or endurance between open and percutaneous repair [57, 119-121]. As the AT, together with soleus and both gastrocnemius muscles (musculotendinous complex), provides ability to raise on toes [85, 122], heel-rise test was used as the basic idea of clinical testing of the strength and functional outcome after ATR $[30,53,54,84]$. Todorov et al. found in their study that device independent measures, like ROM and amount of heel raise are an excellent tool providing similar information compared to isokinetic testing and could be used to evaluate clinical outcome after ATR [121]. Lunsford and Perry proposed 25 repetitions for a grade of normal, when using the standing heel-rise test [84]. Silbernagel with co-workers found good validity and greater ability to detect differences between the injured and the uninjured sides with the heel-rise work that measures not only the number of heel-rise repetitions, but also with height of heel-rise repetitions and comparison to the noninjured side (Limb Symmetry Index) [53, 54]. Using these criteria, we found at the final results in our series $74.19 \%$ of patients in FG and $73.33 \%$ of patients in IG (73.77\% altogether), who regained symmetrical strength after modified percutaneous repair of the ruptured AT under local anesthesia, but also 4 (6.55\%) of 61 patients who were not able to pass the heel-rise test (Test 2) even with the uninjured leg. So, finally there were only 2 (3.27\%) of 61 patients who exhibited reduced strength in a way, that they were not able to pass the heel-rise test with an injured leg, but were able to do this with a non-injured leg.

Beside scoring systems assessment of a patients' functional recovery in comparison to their previous activities could be a simple and useful approach in assessment of different methods, treatment protocols and outcome. Lea and Smith took a very basic approach to outcome; if the patient returned to the preinjury activity level, the

Page 19/33 
outcome was considered good [1]. The results of the presented study were very encouraging in this respect, because $80.64 \%$ of patients in $\mathrm{FG}$ and $80.00 \%$ of patients in IG returned to their previous activities with no limitations and $19.35 \%$ of patients in FG and $20.00 \%$ of patients in IG reported some difficulties, with no statistically significant differences between both groups.

It should be stressed but that the return of strength, ROM and return to work and previous activities after ATR is very much dependent on the patient's interest and motivation and factors like working contract or litigious and compensation reasons. These factors may influence the final outcome much more than for instance the type of treatment or postoperative rehabilitation. These reasons also speak to why we didn't analyze work absence or time to return to activities as it would be difficult to compare professional athletes or those patients motivated to return to work with patients whose insurance issues allowed them to benefit from a lack of recovery.

\section{Conclusions}

The results of our study support the choice of presented modified percutaneous suturing under local anesthesia of the ruptured AT with early mobilization as a reasonable and low costs treatment option for an acute ATR, with lower complication rate in comparison to the results of meta-analyses of other percutaneous methods. It has been shown strong and reliable enough to be used postoperatively with early ankle motion and weightbearing and enabled patients to reach earlier correct pattern of gait without limping, earlier final ROM and earlier better strength in comparison with the use of postoperative rigid immobilization. Patients were able to take off orthosis and to start with exercises in water already after a week and were subjectively more satisfied with such a type of treatment in comparison to patients in the immobilization group. The final results according to ROM, strength, return to previous and sports activities and subjective assessment were comparable in both groups with no statistically significant differences.

\section{List Of Abbreviations}

AT $=$ Achilles tendon

ATR $=$ Achilles tendon rupture

ATRs $=$ Achilles tendon ruptures

$\mathrm{PF}=$ plantar flexion

$\mathrm{DF}=$ dorsal flexion

$\mathrm{ROM}=$ range-of-motion

$F G=$ functional bracing group

IG = immobilization group

DVT = deep venous thrombosis 
VTE $=$ venous thrombembolism

\section{Declarations}

\section{Ethics approval and consent to participate:}

- approved by the National Ethics Committee, No. 54/03/00

- all the participants undersigned Informed/consent form

\section{Consent for publication:}

- no individual details, images or videos that reveal personal's identification are included

\section{Availability of data and materials:}

- the datasets used and/or analysed during the current study are available from the corresponding author on reasonable request.

\section{Competing interests:}

- The authors declare that they have no competing interests.

\section{Funding:}

- The authors declare that they received no funding.

\section{Author's contributions:}

- All authors of the manuscript have contributed to the (whole) study, read and agreed to its content.

\section{Acknowledgement:}

- Not applicable.

\section{Authors' information:}

$-1$

Footnotes: 


\section{References}

1. Lea RB, Smith L. Non-surgical treatment of tendon Achillis ruptures. J Bone Joint Surg Am. 1972;54:1398407.

2. Inglis AE, Scott WN, Sculco TP, Patterson AH. Ruptures of the tendon Achillis. An objective assessment of surgical and non-surgical treatment. J Bone Joint Surg Am. 1976;58:990-9.

3. Nistor L. Surgical and non-surgical treatment of Achilles tendon rupture: a prospective randomized study $\mathrm{J}$ Bone Joint Surg Am. 1981;63:394-9.

4. Cetti R, Christensen SE, Ejsted R, Jensen NM, Jorgensen U. Operative versus nonoperative treatment of Achilles tendon rupture. Am J Sports Med. 1993;21:791-9.

5. McComis GP, Nawoczenski DA, DeHaven KE. Functional bracing for rupture of the Achilles tendon. Clinical results and analysis of ground-reaction forces and temporal data. J Bone Joint Surg Am. 1997;79:1799808.

6. Maffulli N. Rupture of the Achilles tendon. J Bone Joint Surg Am. 1999;81:1019-36.

7. Moller M, Movin T, Granhed H, Lind K, Faxén E, Faxen E, Karlsson J. Acute rupture of tendon Achilles: A prospective randomized study of comparison between surgical and non-surgical treatment. J Bone Joint Surg Br. 2001;3:843-8.

8. Keating JF, Will EM. Operative versus non-operative treatment of acute rupture of tendo Achillis: a prospective randomised evaluation of functional outcome. J Bone Joint Surg Br. 2011;93:1071-8.

9. Twaddle BC, Poon P. Early motion for Achilles tendon ruptures: is surgery important? A randomized, prospective study. Am J Sports Med. 2007;35:2033-8.

10. Willits K, Amendola A, Bryant D, Mohtadi NG, Giffın RJ, Fowler P, Kean CO, Kirkley A. Operative versus nonoperative treatment of acute Achilles tendon ruptures: a multicenter randomized trial using accelerated functional rehabilitation. J Bone Joint Surg Am. 2010;92:2767-75.

11. Nilsson-Helander K, Silbernagel KG, Thomeé R, Faxén E, Olsson N, Eriksson BI, Karlsson J. Acute Achilles tendon rupture: a randomized, controlled study comparing surgical and nonsurgical treatments using validated outcome measures. Am J Sports Med. 2010;38:2186-93.

12. Wallace RGH, Heyes GJ, Michael ALR. The non-operative functional management of patients with a rupture of the tendo Achillis leads to low rates of rerupture. J Bone Joint Surg Br. 2011;93:1362-6.

13. Olsson N, Silbernagel KG, Eriksson BI, Sansone M, Brorsson A, Nilsson-Hellander K, Karlsson J. Stable surgical repair with accelerated rehabilitation versus nonsurgical treatment for acute Achilles tendon ruptures: a randomized controlled study. Am J Sports Med. 2013;41:2867-76.

14. Lantto I, Heikkinen J, Flinkkila T, Ohtonen P, Siira P, Laine V, Leppilahti A prospective randomized trial comparing surgical and nonsurgical treatments of acute Achilles tendon ruptures. Am J Sports Med. 2016;44:2406-14.

15. Inglis AE, Sculco TP. Surgical repair of ruptures of the tendon Achillis. Clin Orthop. 1981;156:160-9.

16. Mandelbaum BR, Myerson MS, Forster R. Achilles tendon ruptures. A new method of repair, early range of motion and functional rehabilitation. Am J Sports Med. 1995;23:392-5. 
17. Mortensen HM, Skov O, Jensen PE. Early motion of the ankle after operative treatment of a rupture of the Achilles tendon. A prospective, randomized clinical and radiographic study. J Bone Joint Surg Am. 1999;81:983-90.

18. Heikkinen J, Lantto I, Flinkkila T, Ohtonen P, Pajala A, Siira P, Leppilahti J. Augmented compared with nonaugmented surgical repair after total Achilles rupture: results of a prospective randomized trial with thirteen or more years of follow-up. J Bone Joint Surg Am. 2016;98:85-92.

19. Lantto I, Heikkinen J, Flinkkila T, Ohtonen P, Kangas J, Siira P, Leppilahti Early Functional Treatment Versus Cast Immobilization in Tension After Achilles Rupture Repair: Results of a Prospective Randomized Trial With 10 or More Years of Follow-Up. Am J Sports Med. 2015;43:2302-9.

20. Ma GWC, Griffith TG. Percutaneous repair of acute closed ruptured Achilles tendon: A new technique. Clin Orthop. 1977;128:247-55.

21. Kosanović M, Čretnik A, Batišta M. Subcutaneous suturing of the ruptured Achilles tendon under local anesthesia. Arch Orthop Trauma Surg. 1994;113:177-9.

22. Amlang MH, Maffulli N, Longo UG, Stübig T, Imrecke J, Hüfner T. Operative Behandlung der Achillessehnenruptur. 2010;113:712-20.

23. Kakiuchi M. A combined open and percutaneous technique for repair of tendon Achillis. Comparison with open repair. J Bone Joint Surg Br. 1995;77:60-3.

24. Buchgraber A, Pässler HH. Percutaneous repair of Achilles tendon rupture. Immobilization versus functional postoperative treatment. Clin Orthop. 1997;341:113-22.

25. Webb JM, Bannister GC. Percutaneous repair of the ruptured tendon Achillis. J. Bone Joint Surg Br. 1999;81:877-80.

26. Assal M, Jung M, Stern R, Rippstein P, Delmi M, Hoffmeyer P. Limited open repair of Achilles tendon ruptures. A technique with a new instrument and findings of a prospective multicenter study. J Bone Joint Surg Am. 2002;84:161-70.

27. Ngai WYH, Chan SCF. An uncomplicated method for minimally invasive Achilles tendon repair. J Foot Ankle Surg. 2010;49:208-11.

28. Hsu AR, Jones CP, Cohen BE, Davis WH, Ellington JK, Anderson RB. Clinical outcomes and complications of Percutaneous Achilles Repair System versus open technique for acute Achilles tendon rupture. Foot Ankle Int. 2015;36:1279-86.

29. Soubeyrand M, Serra-Tosio G, Campagna R, Molina V, Sitbon P, Biau DJ. Intraoperative ultrasonography during percutaneous Achilles tendon repair. Foot Ankle Int. 2010;31:1069-74.

30. Čretnik A, Kosanović M, Smrkolj V. Percutaneous versus open repair of the ruptured Achilles tendon: a comparative study. Am J Sports Med. 2005;33:1369-79.

31. Halasi T, Tallay A, Berkes I. Percutaneous Achilles tendon repair with and without endoscopic control. Knee Surg Sports Traumatol Arthrosc. 2003;11:409-14.

32. Tang KL, Therman H, Dai G, Chen GX, Guo L, Yang L. Arthroscopically assisted percutaneous repair of fresh closed Achilles tendon rupture by Kessler's suture. Am J Sports Med. 2007;35:589-96.

33. Doral MN, Bozkurt M, Turhan E, Ayvaz M, Atay OA, Uzumcugil A, Leblebicioglu G, Kaya D, Aydog T. Percutaneous suturing of the ruptured Achilles tendon using endoscopic control. Arch Orthop Trauma 
Surg. 2009;129:1093-101.

34. Carter TR, Fowler PJ, Blokker C. Functional postoperative treatment of Achilles tendon repair. Am J Sports Med. 1992;20:459-62.

35. Wong J, Barrass V, Maffulli N. Quantitative review of operative and nonoperative management of Achilles tendon ruptures. Am J Sports Med. 2002;30:565-75.

36. Wang D, Sandlin MI, Cohen JR, Lord EL, Petrigliano FA, Nelson F, SooHoo NF. Operative versus nonoperative treatment of acute Achilles tendon rupture: An analysis of 12,570 patients in a large healthcare database. Foot Ankle Surg. 2017;21:250-3.

37. Kocher MS, Bishop J, Marshall R, Briggs KK, Hawkins RJ. Operative versus Nonoperative Management of Acute Achilles Tendon Rupture. Expected-value Decision Analysis. Am J Sports Med. 2002;30:783-90.

38. Bhandari M, Guyatt GH, Siddiqui F, Morrow F, Busse J, Leighton RK, Sprague S, Schemitsch EH. Treatment of acute Achilles tendon ruptures: a systematic overview and meta-analysis. Clin Orthop Relat Res. 2002;400:190-200.

39. Khan RJ, Fick D, Keogh A, Crawford J, Brammar T, Parker M. Treatment of acute Achilles tendon ruptures: a meta-analysis of randomized, controlled trials. J Bone Joint Surg Am. 2005;87:2202-10.

40. Wilkins R, Bisson LJ. Operative versus nonoperative management of acute Achilles tendon ruptures: a quantitative systematic review of randomized controlled trials. Am J Sports Med. 2012;40:2154-60.

41. Deng S, Sun Z, Zhang C, Chen G, Li J. Surgical treatment versus conservative management for acute Achilles tendon rupture: a systematic review and meta-analysis of randomized controlled trials. J Foot Ankle Surg. 2017;56:1236-43.

42. van der Eng DM, Schepers T, Goslings JC, Schep NW. Rerupture rate after early weightbearing in operative versus conservative treatment of Achilles tendon ruptures: a meta-analysis. J Foot Ankle Surg. 2013;52:622-8.

43. Jones MP, Khan RJ, Carey Smith RL. Surgical interventions for treating acute achilles tendon rupture: key findings from a recent Cochrane review. J Bone Joint Surg Am. 2012;94:e88.

44. Khan RJ, Carey Smith RL. Surgical interventions for treating acute Achilles tendon ruptures. Cochrane Database Syst Rev. 2010;9:CD003674.

45. Ochen Y, Beks RB, van Heijl M, Hietbrink F, Leenen LPH, van der Velde D, Heng M, van der Meijden O, Groenwold RHH, Houwert RM. Operative treatment versus nonoperative treatment of Achilles tendon ruptures: systematic review and meta-analysis. 2019;364:k5120.

46. Wu Y, Mu Y, Yin L, Wang Z, Liu W, Wan H. Complications in the management of acute Achilles tendon rupture. A systematic review and network meta-analysis of 2060 patients. Am J Sports Med. 2019;40:2154-60.

47. Soroceanu A, Sidhwa F, Aarabi S, Kaufman A, Glazebrook M. Surgical versus nonsurgical treatment of acute Achilles tendon rupture: a meta-analysis of randomized trials. J Bone Joint Surg Am. 2012;94:213643.

48. Huang J, Wang C, Ma X, Wang X, Zhang C, Chen L. Rehabilitation regimen after surgical treatment of acute Achilles tendon ruptures: a systematic review with meta-analysis. Am J Sports Med. 2015;43:1008-16. 
49. Eliasson P T, Agergaard A, Couppe C, Svensson R, Hoeffner R, Warming S, Warming N, Holm C, Jensen MH, Krogsgaard M, Kjaer M, Magnusson SP. The ruptured Achilles tendon elongates for 6 months after surgical repair regardless of early or late weightbearing in combination with ankle mobilization: a randomized clinical trial. Am J Sports Med. 2018;46:2492-502.

50. Kangas J, Pajala A, Ohtonen P, Leppilahti J. Achilles tendon elongation after rupture repair: a randomized comparison of 2 postoperative regimens. Am J Sports Med. 2007;35:59-64.

51. Lee SJ, Sileo MJ, Kremenic IJ, Orishimo K, Ben-Avi S, Nicholas SJ, McHugh M. Cyclic loading of 3 Achilles tendon repairs simulating early postoperative forces. Am J Sports Med. 2009;37:786-90.

52. Clanton TO, Haytmanek CT, Williams BT, Civitaresse DM, Turnbull TL, Massey MB, Wijdicks CA, LaPrade RF. A biomechanical comparison of an open repair and 3 minimally invasive percutaneous Achilles tendon repairs during a simulated progressive rehabilitation protocol. Am J Sports Med. 2015;43:1957-64.

53. Silbernagel KG, Nilsson-Helander K, Thomee R, Eriksson BI, Karlsson J. A new measurement of heel-rise endurance with the ability to detect functional deficits in patients with Achilles tendon rupture. Knee Surg Sports Traumatol Arthrosc. 2010;18:258-64.

54. Silbernagel KG, Steele R, Manal K. Deficits in heel-rise height and Achilles tendon elongation occur in patients recovering from an Achilles tendon rupture. Am J Sports Med. 2012;40:1564-71.

55. Rosso C, Vavken P, Polzer C, Buckland DM, Studler U, Weisskopf L, Lottenbach M, Müller AM, Valderrabano V. Long-term outcomes of muscle volume and Achilles tendon length after Achilles tendon ruptures. Knee Surg Sports Traumatol Arthrosc. 2013;21:1369-77.

56. Hockenbury RT, Johns JC. A biomechanical in vitro comparison of open versus percutaneous repair of tendon Achilles. Foot Ankle Int. 1990;11:67-72.

57. Bradley JP, Tibone JE. Percutaneous and open surgical repairs of Achilles tendon ruptures. A comparative study. Am J Sports Med. 1990;18:188-95.

58. Klein W, Lang D, and Saleh M. The use of the Ma-Griffith technique for percutaneous repair of fresh ruptured tendo Achillis. Chir Organi Mov. 1991;76:223-8.

59. Čretnik A, Žlajpah L, Smrkolj V, Kosanović M. The strength of percutaneous methods of repair of the Achilles tendon: a biomechanical study. Med Sci Sports Exerc. 2000;32:16-20.

60. Čretnik A, Kosanović M, Smrkolj V. Percutaneous suturing of the ruptured Achilles tendon under local anesthesia. J Foot Ankle Surg. 2004;43:72-81.

61. Petri M, Ettinger M, Dratzidis A, Liodakis E, Brand S, Albrecht UV, Hurschler C, Krettek C, Jagodzinski M. Comparison of three suture techniques and three suture materials on gap formation and failure load in ruptured tendons: a human cadaveric study. Arch Orthop Trauma Surg. 2012;132:649-54.

62. Mortensen NH, Saether J. Achilles tendon repair: a new method of Achilles tendon repair tested on cadaverous materials. J Trauma. 1991;31:381-4.

63. Watson TW, Jurist KA, Yang KH, Shen KL. The strength of Achilles tendon repair: an in vitro study of the biomechanical behavior in human cadaver tendons. Foot Ankle Int. 1995;16:191-5.

64. Longo UG, Forriol F, Campi S, Maffulli N, Denaro V. A biomechanical comparison of the primary stability of two minimally invasive techniques for repair of ruptured Achilles tendon. Knee Surg Sports Traumatol Arthrosc. 2012;20:1392-7. 
65. Gebauer M, Timo Beil F, Beckmann J, Sarvary AM, Ueblacker P, Ruecker AH, Holste J, Meenen NM. Mechanical evaluation of different techniques for Achilles tendon repair. Arch Orthop Trauma Surg. 2007;127:795-9.

66. Gerdes MH, Brown TD, Bell AL, Baker JA, Levson M, Layer S. A flap augmentation technique for Achilles tendon repair. Postoperative strength and functional outcome. Clin Orthop Relat Res. 1992;280:241-6.

67. Zandbergen RA, de Boer SF, Swiestra BA, Day J, Kleinrensink GJ, Beumer A. Surgical treatment of Achilles tendon rupture: examination of strength of 3 types of suture techniques in a cadaver model. Acta Orthop. 2005;76:408-11.

68. McCoy BW, Haddad SL. The strength of Achilles tendon repair: a comparison of three suture techniques in human cadaver tendons. Foot Ankle Int. 2010;31:701-5.

69. Ismail M, Karim A, Shulman R, Amis A, Calder J. The Achillon ${ }^{\circledR}$ Achilles tendon repair: is it strong enough? Foot Ankle Int. 2008;29:808-13.

70. Herbort M, Haber A, Zantop T, Gosheger G, Rosslenbroich S, Raschke MJ, Petersen W. Biomechanical comparison of the primary stability of suturing Achilles tendon rupture: a cadaver study of Bunnell and Kessler techniques under cyclic loading conditions. Arch Orthop Trauma Surg. 2008;128:1273-7.

71. Cottom JM, Baker JS, Richardson PE, Maker JM. Evaluation of a new knotless suture anchor repair in acute Achilles tendon ruptures: a biomechanical comparison of three techniques. J Foot Ankle Surg. 2017;56:423-7.

72. Demetracopoulos CA, Gilbert SL, Young E, Baxter JR, Deland JT. Limited-open Achilles tendon repair using locking sutures versus nonlocking sutures: an in vitro model. Foot Ankle Int. 2014;35:612-8.

73. Hufard B, O'Loughlin PF, Wright T, Deland J, Kennedy JG. Achilles tendon repair: Achillon system vs. Krackow suture: An anatomic in vitro biomechanical study. Clinical Biomechanics. 2008;23:1158-64.

74. Dekker RG, Qin C, Lawton C, Muriuki MG, Havey RM, Alshouli M, Patwardhan AG, Kadakia A. A biomechanical comparison of limited open versus Krackow Repair for Achilles tendon rupture. Foot Ankle Orthopaedics. 2017;2:1-7.

75. Thompson TC. A test for rupture of the tendo Achillis. Acta Orthop Scand. 1962;32:461-5.

76. Cuttica DJ, Hyer CF, Berlet GC. Intraoperative value of the Thompson test. J Foot Ankle Surg. 2015;54:99101.

77. Citak M, Knoblach K, Albrecht K, Krettek C, Hufner T. Anatomy of the sural nerve in a computer-assisted model: implications for surgical minimal-invasive Achilles tendon repair. Br J Sports Med. 2007;41:456458.

78. Apaydin N, Bozkurt M, Loukas M, Vefali H, Tubbs RS, Esmer AF. Relationships of the sural nerve with the calcaneal tendon: an anatomical study with surgical and clinical implications. Surg Radiol Anat. 2009;31;775-80.

79. Kitaoka HB, Alexander IJ, Adelaar RS, Nunley JA, Myerson MS, Sanders M. Clinical rating systems for the ankle-hindfoot, midfoot, hallux, and lesser toes. Foot Ankle Int. 1994;15:349-53.

80. Ibrahim T, Beiri A, Azzabi M, Best AJ, Taylor GJ, Menon DK. Reliability and validity of the subjective component of the American Orthopaedic Foot and Ankle Society clinical rating scales. J Foot Ankle Surg. 2007;46:65-74. 
81. Ceccarelli F, Calderazzi F, Pedrazzi G. Is there a relation between AOFAS Ankle-hindfoot score and SF-36 in evaluation of Achilles ruptures treated by percutaneous technique? J Foot Ankle Surg. 2014;53:16-21.

82. Leppilahti J, Forsman K, Puranen J, Orava S. Outcome and prognostic factors of Achilles rupture repair using a new scoring method. Clin Orthop. 1998;346:152-61.

83. Ryf C, Weyman A. The Neutral Zero Method - A Principle of Measuring Joint Function. Injury. 1995;26(Suppl 1):1-11.

84. Lunsford BR, Perry J. The standing heel-rise test for ankle plantar flexion: criterion for normal. Phys Ther. 1995;75:694-8.

85. Bressel E, McNair PJ. Biomechanical behavior of the plantar flexor muscle-tendon unit after an Achilles tendon rupture. Am J Sports Med. 2001;29:321-6.

86. Schepull T, Aspenberg P. Early Controlled Tension Improves the Material Properties of Healing Human Achilles Tendons After Ruptures. A Randomized Trial. Am J Sports Med. 2013;29:321-6.

87. Aufwerber S, Heijne A, Edman G, Silbernagel KG, Ackermann PW. Does early functional mobilization affect long-term outcomes after an Achilles tendon rupture? A randomized clinical trial. Orthop J Sports Med. 2019;8(3), 2325967120906522.

88. Davidson CJ, Ganion LR, Gehlsen GM, Verhoestra B, Roepke JE, Sevier TL. Rat tendon morphologic and functional changes resulting from soft tissue mobilization. Med Sci Sports Exerc. 1997;29:313-9.

89. Mullaney MJ, McHugh MP, Tyler TF, Nicholas SJ, Lee SJ. Weakness in end-range plantar flexion after Achilles tendon repair. Am J Sports Med. 2006;34:1120-5.

90. McClelland D, Maffulli N. Percutaneous repair of ruptured Achilles tendon. J R Coll Surg Edin. 2002;47:6138.

91. Carmont MR, Maffulli N. Modified percutaneous repair of the Achilles tendon. Knee Surg Sports Traumatol Arthrosc. 2008;16:199-203.

92. Čretnik A, Košir R, Kosanović M. Incidence and outcome of operatively treated Achilles tendon rupture in the elderly. Foot Ankle Int. 2010;31:14-8.

93. Zhao C, Amadio PC, Tanaka T, Kutsumi K, Tsubone T, Zobitz ME, An K. Effect of gap size on gliding resistance after flexor tendon repair. J Bone Joint Surg Am. 2004;86:2482-8.

94. Benthien RA, Aronow MS, Doran-Diaz V, Sullivan RJ, Adams DJ. Cyclic loading of Achilles tendon repairs: a comparison of polyester and polyblend suture. Foot Ankle Int. 2006;27:512-8.

95. Jaakkola JI, Hutton WC, Beskin JL, Lee GP. Achilles tendon rupture repair: biomechanical comparison of the triple bundle technique versus the Krakow locking loop technique. Foot Ankle Int. 2000;21:14-7.

96. Lim J, Dalal R, Waseem M. Percutaneous vs. open repair of the ruptured Achilles tendon - a prospective randomized controlled study. Foot Ankle Int . 2001;22:559-68.

97. Haji A, Sahai A, Symes A, Vyas JK. Percutaneous versus open tendo Achillis repair. Foot Ankle Int. 2004;25:215-8.

98. Bartel AFP, Elliot AD, Roukis TS. Incidence of complications after Achillon ${ }^{\circledR}$ mini-open suture system for repair of acute midsubstance Achilles tendon ruptures: a systematic review. J Foot Ankle Surg. 2014;53:744-6. 
99. Yang B, Liu Y, Kan S, Zhang D, Xu H, Liu F, Ning G, Feng S. Outcomes and complications of percutaneous versus open repair of acute Achilles tendon rupture: a metaanalysis. Int J Surg. 2017;40:178-86.

100. Lo IK, Kirkley A, Nonweiler B, Kumbhare DA. Operative versus nonoperative treatment of acute Achilles tendon ruptures: a quantitative review. Clin J Sport Med. 1997;7:207-11.

101. Metz R, van der Heijden GJMG, Verleisdonk E-JMM, Kolfschoten N, Verhofstad MHJ, van der Werken C. Effect of complications after minimally invasive surgical repair of Acute Achilles tendon ruptures: report on 211 cases. Am J Sports Med. 2011;39:820-4.

102. Pajala A, Kangas J, Ohtonen P, Leppilahti J. Repeat rupture and deep infection following treatment of total Achilles tendon rupture. J Bone Joint Surg Am. 2002;84:2016-21.

103. Saxena A, Maffulli N, Nguyen A, Li A. Wound complications from surgeries pertaining to the Achilles tendon. J Am Podiatr Med Assoc. 2008;98:95-101.

104. Shepull T, Kvist J, Norrman H, Trinks M, Berlin G, Aspenberg P. Autologous platelets have no effect on the healing of human Achilles tendon ruptures. Am J Sports Med. 2011;39:38-47.

105. Grassi A, Amendola A, Samuelsson K, Svantesson E, Romagnoli M, Bondi A, Mosca M, Zaffagnini S. Minimally invasive versus open repair for acute Achilles tendon rupture. Meta-analysis showing reduced complications, with similar outcomes after minimally invasive surgery. J Bone Joint Surg Am. 2018;100:1969-81.

106. Labib SA, Hofler CE, Shah JN, Rolf R, Tingan A. The Gift box open Achilles tendon repair method: a retrospective clinical series. J Foot Ankle Surg. 2016;55:39-44.

107. Aibinder WR, Patel A, Arnouk J, El-Gendi H, Korshunov Y, Mitgang J, Uribe J. The rate of sural nerve violation using the Achillon device: a cadaveric study. Foot Ankle Int. 2013;34:870-5.

108. Majewski M, Rohrbach M, Czaja S, Ochsner P. Avoiding sural nerve injuries during percutaneous Achilles tendon repair. Am J Sports Med. 2006;34:793-8.

109. Patel A, Ogawa B, Charlton T, Thordarson D. Incidence of deep vein thrombosis and pulmonary embolism after Achilles tendon rupture. Clin Orthop Relat Res. 2012;470:270-4.

110. Calder JDF, Freeman R, Domeij-Arverud E, van Dijk CN, Ackermannn PW. Meta-analysis and suggested guidelines for prevention of venous thromboembolism (VTE) in foot and ankle surgery. Knee Surg Sports Traumatol Arthrosc. 2016;24:1409-20.

111. Aufwerber S, Heijne A, Edman G, Silbernagel KG, Ackermann PW. Early mobilization does not reduce the risk of deep venous thrombosis after Achilles tendon rupture: a randomized controlled trial. Knee Surg Sports Traumatol Arthrosc. 2020;28:312-9.

112. Falck-Ytter Y, Francis CW, Johanson NA, Curley C, Dahl OE, Schulman S, Ortel TL, Pauker SG, Colwell CW Jr. Prevention of VTE in orthopedic surgery patients: antithrombotic therapy and prevention of thrombosis, 9th ed: American College of Chest Physicians evidence-based clinical practice guidelines. Chest. 2012;141(2 Suppl):278S-325S.

113. Zellers JA, Christensen M, Kjær IL, Rathleff MS, Silbernagel KG. Defining components of early functional rehabilitation for acute Achilles tendon rupture. A systematic review. Orthop J Sports Med. 2019;7(11), 2325967119884071.

114. Frankewycz B, Krutsch W, Weber J, Ernstberger A, Nerlich M, Pfeifer CG. Rehabilitation of Achilles tendon ruptures: is early functional rehabilitation daily routine? Arch Orthop Trauma Surg. 2017;137:333-40. 
115. Nilsson-Helander K, Thomeé R, Silbernagel KG, Thomee P, Faxén E, Eriksson BI, Karlsson J. The Achilles tendon total rupture score (ATRS). Development and validation. Am J Sports Med. 2007;35:421-6.

116. Cöster M, Karlsson MK, Nilsson JÅ, Carlsson $\AA$. Validity, reliability, and responsiveness of a self-reported foot and ankle score (SEFAS). Acta Orthopaedica. 2012;83:197-203.

117. Aktas S, Kocaaoglu B. Open versus minimal invasive repair with Achillon device. Foot Ankle Int. 2009;30:391-7.

118. Washburn SD, Caiozzo VJ, Wills CA, Hunt BJ, Prietto CA. Alterations in the in-vivo torque-velocity relationship after Achilles tendon rupture. Further evidence of speed- specific impairment. Clin Orthop. 1992;279:237-45.

119. Goren D, Ayalon M, Nyska M. Isokinetic strength and endurance after percutaneous and open surgical repair of Achilles tendon ruptures. Foot Ankle Int. 2005;26:286-90.

120. Fitzgibbons RE, Hefferon J, Hill J. Percutaneous Achilles tendon repair. Am J Sports Med. 1993;21:724-7.

121. Todorov A, Schaub F, Blanke F, Heisterbach P, Sachser F, Gösele A, Majewski M. Clinical assessment is sufficient to allow outcome evaluation following surgical management of Achilles tendon ruptures. Muscles Ligaments Tendons J. 2015;5:68-72.

122. O'Brien M. The anatomy of the Achilles tendon. Foot Ankle Clin N Am. 2005;10:225-38.

\section{Figures}
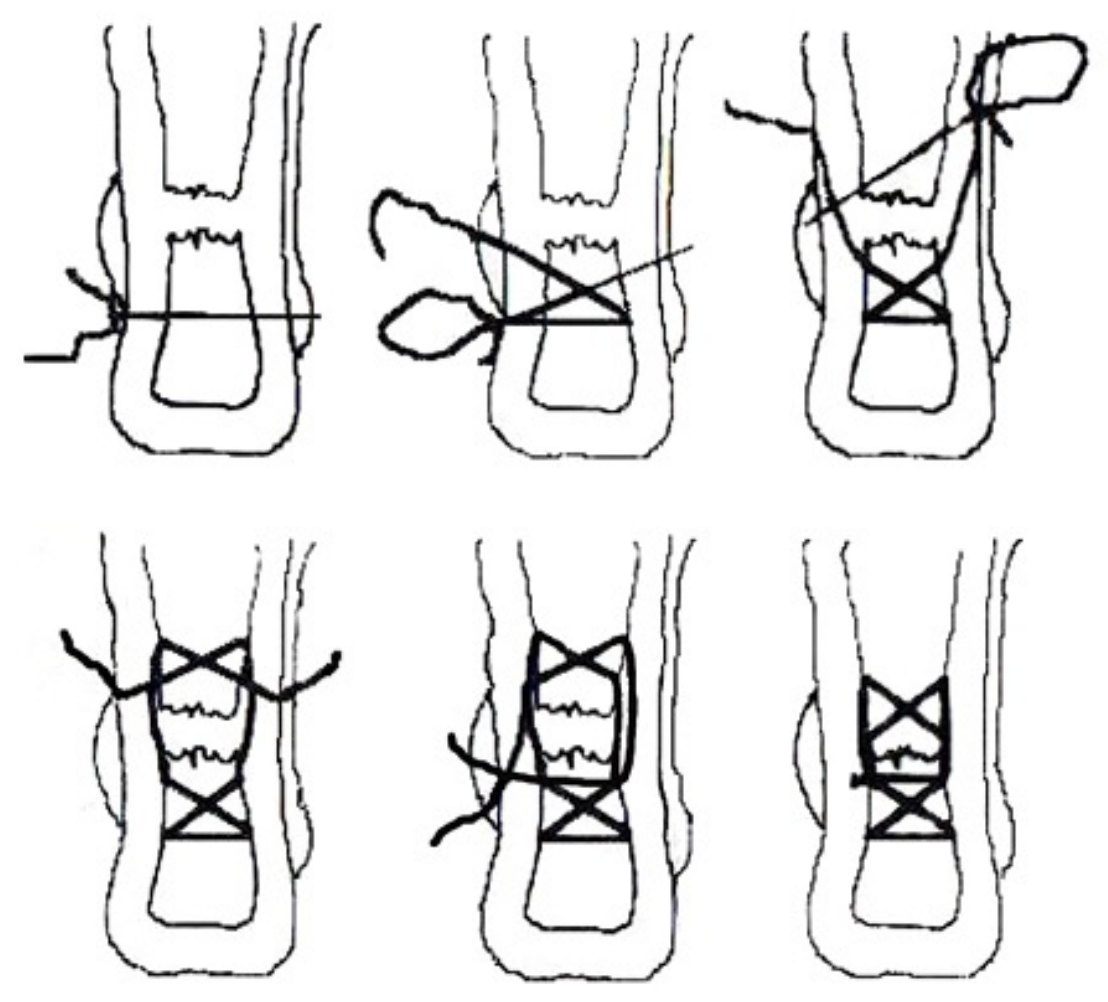

\section{Figure 1}

Modified repair - schematically [21] 


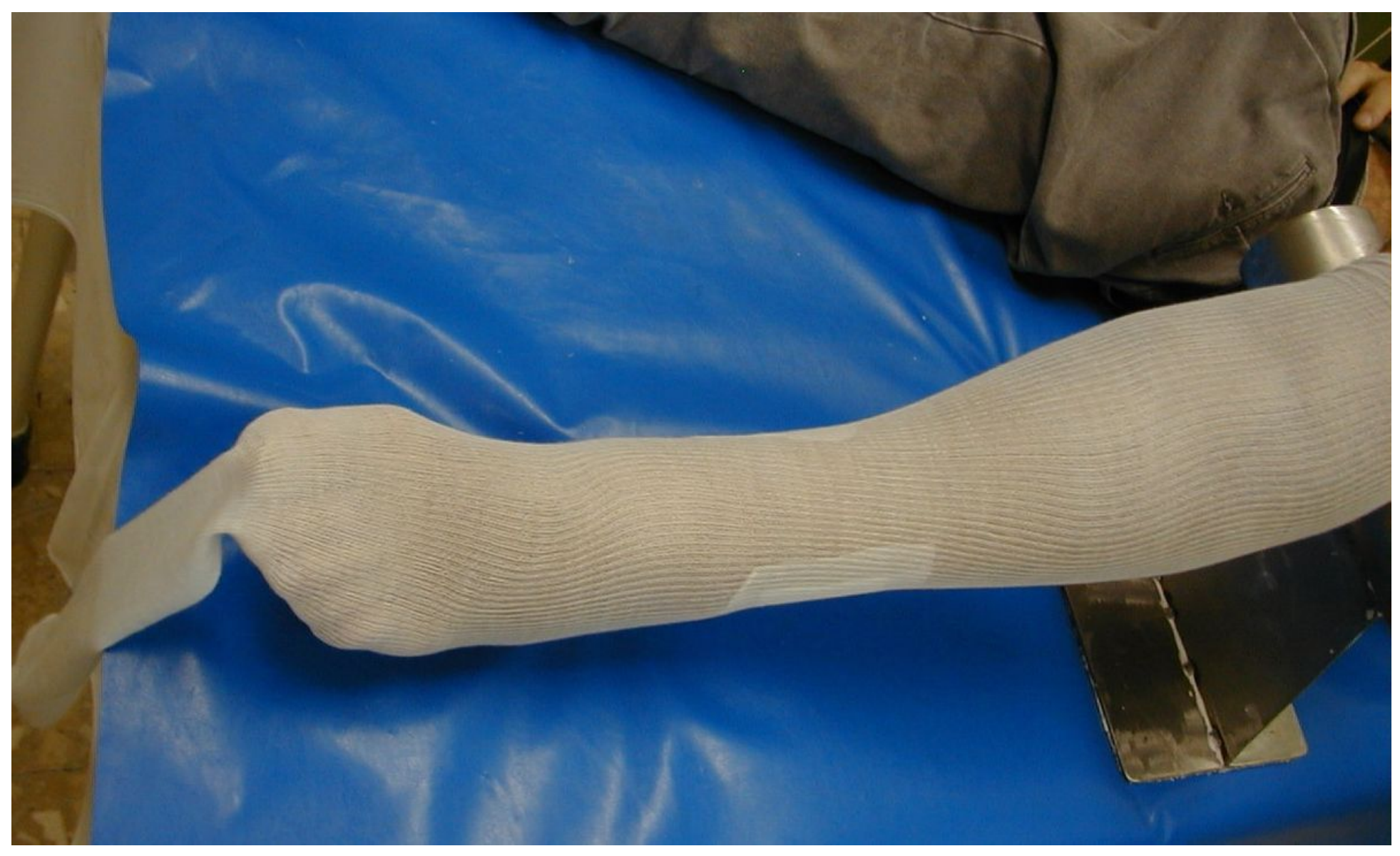

Figure 2

Stockinette 


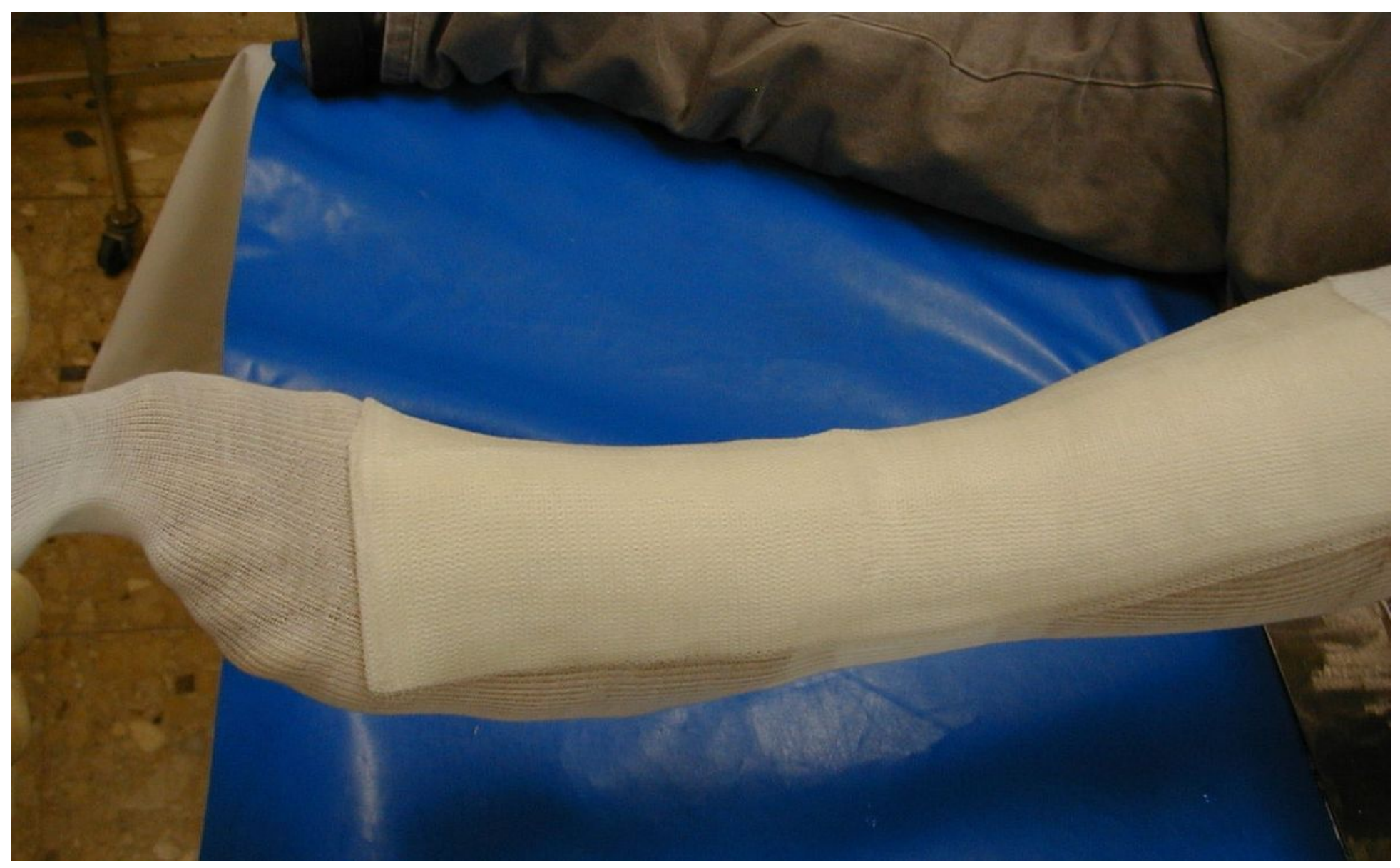

Figure 3

Splint of several layers of softcast 


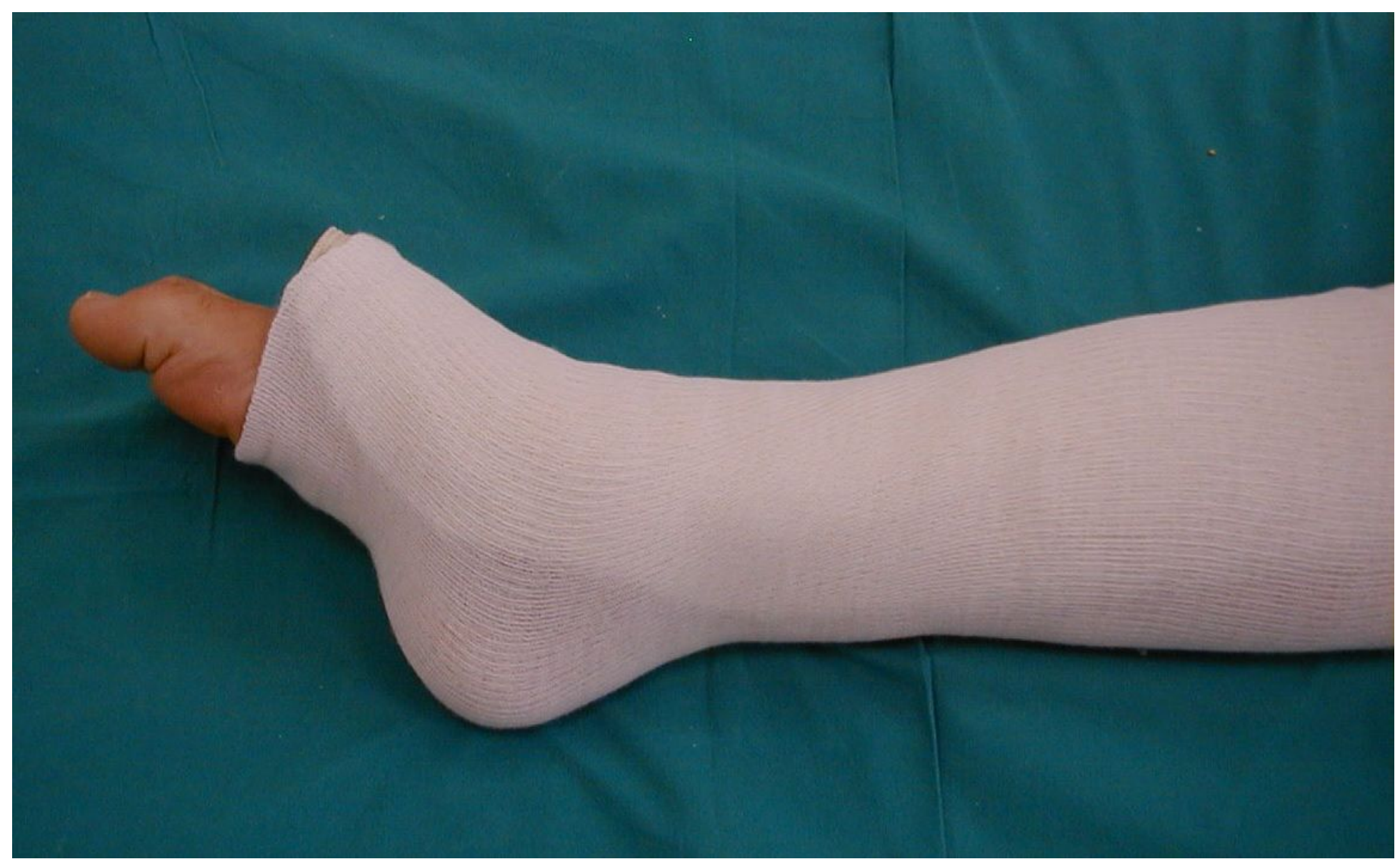

\section{Figure 4}

Functional orthosis

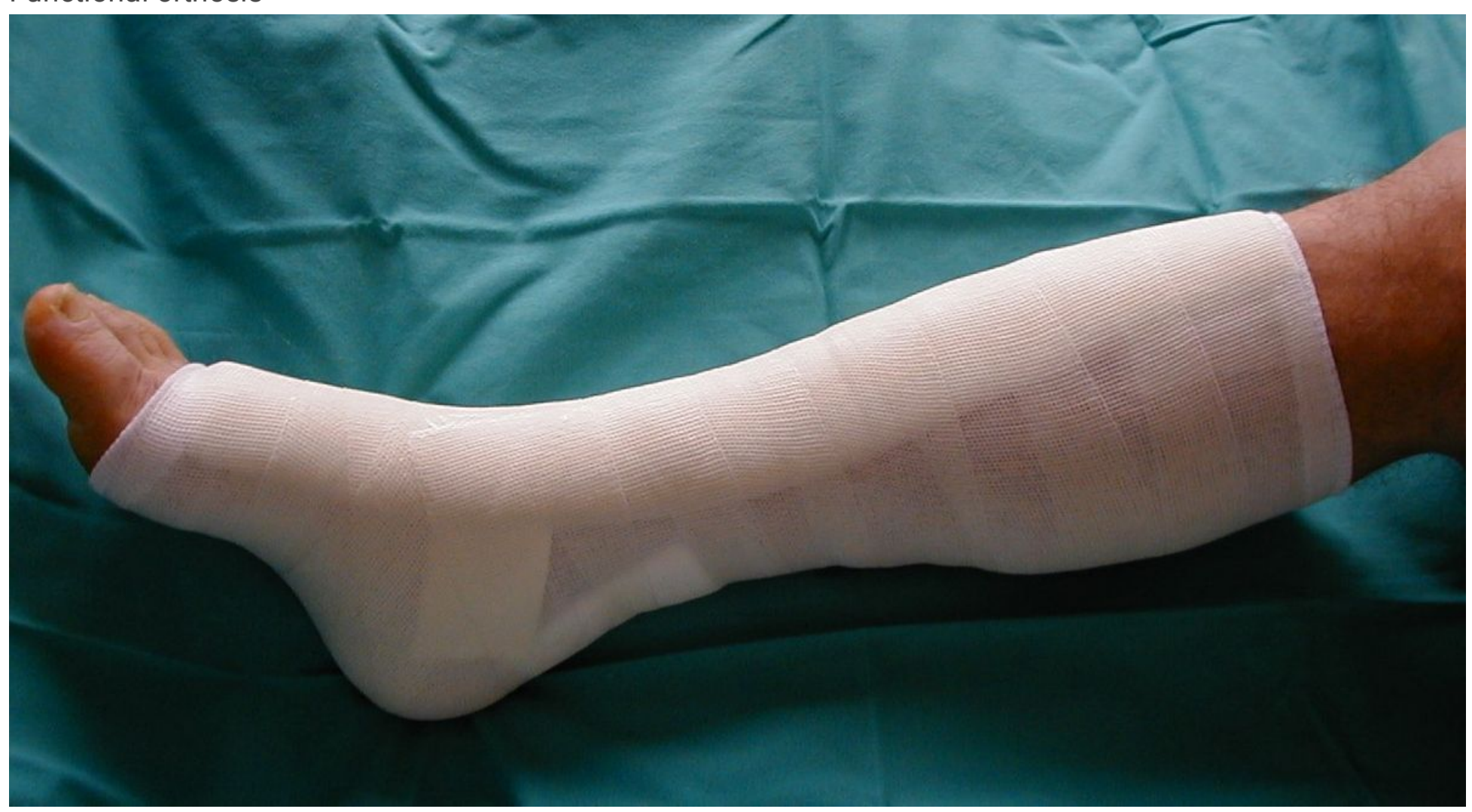

Page 32/33 
Figure 5

Rigid immobilization

\section{Supplementary Files}

This is a list of supplementary files associated with this preprint. Click to download.

- CONSORT2010FlowDiagram.doc 